\title{
Cell culture-based production and in vivo characterization of purely clonal defective interfering influenza virus particles
}

Marc D. Hein ${ }^{1}$, Prerna Arora ${ }^{2,3}$, Pavel Marichal-Gallardo ${ }^{4}$, Michael Winkler ${ }^{2,3}$, Yvonne Genzel $^{4}$, Stefan Pöhlmann ${ }^{2,3}$, Klaus Schughart ${ }^{5,6,7}$, Sascha Y. Kupke ${ }^{4^{*}}$ (D) and Udo Reichl $1^{1,4}$

\begin{abstract}
Background: Infections with influenza A virus (IAV) cause high morbidity and mortality in humans. Additional to vaccination, antiviral drugs are a treatment option. Besides FDA-approved drugs such as oseltamivir or zanamivir, virus-derived defective interfering (DI) particles (DIPs) are considered promising new agents. IAV DIPs typically contain a large internal deletion in one of their eight genomic viral RNA (VRNA) segments. Consequently, DIPs miss the genetic information necessary for replication and can usually only propagate by co-infection with infectious standard virus (STV), compensating for their defect. In such a co-infection scenario, DIPs interfere with and suppress STV replication, which constitutes their antiviral potential.
\end{abstract}

Results: In the present study, we generated a genetically engineered MDCK suspension cell line for production of a purely clonal DIP preparation that has a large deletion in its segment 1 (DI244) and is not contaminated with infectious STV as egg-derived material. First, the impact of the multiplicity of DIP (MODIP) per cell on DI244 yield was investigated in batch cultivations in shake flasks. Here, the highest interfering efficacy was observed for material produced at a MODIP of 1E-2 using an in vitro interference assay. Results of RT-PCR suggested that DI244 material produced was hardly contaminated with other defective particles. Next, the process was successfully transferred to a stirred tank bioreactor ( $500 \mathrm{~mL}$ working volume) with a yield of $6.0 \mathrm{E}+8 \mathrm{PFU} / \mathrm{mL}$ determined in genetically modified adherent MDCK cells. The produced material was purified and concentrated about 40-fold by membranebased steric exclusion chromatography (SXC). The DI244 yield was $92.3 \%$ with a host cell DNA clearance of $97.1 \%$ (99.95\% with nuclease digestion prior to SXC) and a total protein reduction of $97.2 \%$. Finally, the DIP material was tested in animal experiments in D2(B6).A2G-Mx $1^{r / r}$ mice. Mice infected with a lethal dose of IAV and treated with DIP material showed a reduced body weight loss and all animals survived.

(Continued on next page)

\footnotetext{
* Correspondence: kupke@mpi-magdeburg.mpg.de

${ }^{4}$ Max Planck Institute for Dynamics of Complex Technical Systems, Bioprocess Engineering, Magdeburg, Germany

Full list of author information is available at the end of the article
}

(C) The Author(s). 2021 Open Access This article is licensed under a Creative Commons Attribution 4.0 International License, which permits use, sharing, adaptation, distribution and reproduction in any medium or format, as long as you give appropriate credit to the original author(s) and the source, provide a link to the Creative Commons licence, and indicate if changes were made. The images or other third party material in this article are included in the article's Creative Commons licence, unless indicated otherwise in a credit line to the material. If material is not included in the article's Creative Commons licence and your intended use is not permitted by statutory regulation or exceeds the permitted use, you will need to obtain permission directly from the copyright holder. To view a copy of this licence, visit http://creativecommons.org/licenses/by/4.0/ The Creative Commons Public Domain Dedication waiver (http://creativecommons.org/publicdomain/zero/1.0/) applies to the data made available in this article, unless otherwise stated in a credit line to the data. 
(Continued from previous page)

Conclusion: In summary, experiments not only demonstrated that purely clonal influenza virus DIP preparations can be obtained with high titers from animal cell cultures but confirmed the potential of cell culture-derived DIPs as an antiviral agent.

Keywords: Influenza A virus, Antiviral, Genetically engineered MDCK cells, Defective interfering particles, DI244, Cell culture-based production, Scale up, Steric exclusion chromatography, Animal experiments

\section{Background}

Every year, infections with influenza A virus (IAV) result in about 300,000-650,000 deaths worldwide [1]. Occasional IAV pandemics can even cause millions of deaths, e.g., approximately 40 million deaths are attributed to the "Spanish flu" from 1918 [2, 3]. Considering the time required to develop and produce a vaccine, the availability of antivirals as a fast countermeasure seems to be indispensable for pandemic preparedness. Additionally, antivirals can also be used as a supplement to vaccination to cope with annual IAV epidemics. Antivirals currently in use are small molecules like oseltamivir and zanamivir [4-6]. However, use of these drugs is compromised by the existence of circulating resistant IAV strains [7, 8]. Thus, novel treatment modalities are clearly needed.

One such treatment modality could be the administration of defective interfering (DI) particles (DIPs) [9-13]. DIPs are virus mutants that arise naturally due to errors in the replication of the genomic viral RNA (vRNA) [14, 15]. IAV DIPs typically harbor a large central deletion in the open reading frame of one of their eight vRNA segments [16]. In addition, a DIP carrying numerous point mutations has been identified recently [17]. Due to their deletions, conventional DIPs are not capable to synthesize all full-length (FL) proteins on their own [18] but require co-infection with infectious standard virus (STV) for replication. Here, DIPs interfere with and suppress STV replication and almost exclusively noninfectious DIPs are released $[19,20]$. It is speculated that this is due to faster replication of short DI vRNAs outcompeting STV for limited cellular and viral resources $[16,21,22]$.

It was shown previously that administration of a specific IAV DIP containing a deletion in segment 1 (Seg1) vRNA, called DI244, resulted in an antiviral effect in animals [10-13, 23]. More specifically, treatment with DI244 containing material (produced in embryonated chicken eggs) resulted in reduced clinical symptoms in IAV-infected ferrets and protection of mice against an otherwise lethal dose of IAV [10, 23, 24]. DI244 was also reported to protect against a variety of other IAV strains $[10,23]$.

As DIP replication usually depends on STV coinfection, the egg-derived DIP material produced and tested in animal experiments so far has been always a mixture of DI244 and infectious STV [25]. Moreover, to eliminate potentially harmful STV in therapy, it was inactivated by UV irradiation. Yet, this also inactivated parts of the produced DIPs and consequently reduced their interfering efficacy [10]. Previously, we and others have reported methods for production of purely clonal DIP populations, overcoming the need of STV inactivation [26, 27]. These are based on genetically modified adherent and suspension cell lines expressing polymerase basic protein 2 (PB2) encoded by IAV Seg1 vRNA.

In the present study, we propose a cell culture-based production process using a suspension MDCK cell line expressing PB2 (MDCK-PB2(sus)) for production of purely clonal DI244 without STV contamination. Shake flask experiments demonstrated that the resulting DI244 yield and the interfering efficacy of the produced material strongly depended on the multiplicity of DIP (MODIP) per cell applied for infection. After scale-up to a stirred tank bioreactor (STR), the DIP material was purified using membrane-based steric exclusion chromatography (SXC). This allowed to increase its concentration about 40-fold. Finally, the DI244 material was tested in mice infected with a lethal dose of STV.

\section{Results}

\section{DI244 production yields depend on MODIP}

In order to produce DI244 without use of a helper virus, a purely clonal DI244 seed, generated by reverse genetics, and a genetically engineered suspension cell line expressing the viral PB2 protein, called MDCK-PB2(sus), was used. The expression of PB2 was monitored over several passages with a western blot. The cell line showed very comparable maximum specific growth rates to the parental suspension MDCK cell line (Additional file 1: Fig. S1). For process evaluation, the impact of the MODIP on DI244 yield was investigated. While earlier DI244 release and a higher yield can be expected for higher MODIPs, infections with higher virus concentrations can result in a strong de novo generation of other DI vRNAs [19], which would contaminate the DI244 product. Therefore, four MODIPs ranging from $1 \mathrm{E}-1$ to 1E-4 were tested. For process monitoring, the hemagglutination assay, real-time reverse transcription 
qPCR (real-time RT-qPCR) and plaque assay (DI244 titer) were used.

The MODIP screening revealed that hemagglutinin (HA) and DI244 titer reached their respective maximum value earlier for higher MODIPs (Fig. 1a, b). In line with this, the viable cell concentration (VCC) decreased faster for higher MODIPs, which may be explained by an earlier onset of cell apoptosis with faster virus propagation (Fig. 1c). Maximum HA $\left(2.62-2.65 \log _{10} \mathrm{HAU} / 100 \mu \mathrm{L}\right)$ and DI244 titers $(4.80 \mathrm{E}+7-1.08 \mathrm{E}+8$ plaque forming units per $\mathrm{mL}(\mathrm{PFU} / \mathrm{mL})$ ) were comparable for all MODIPs, except for MODIP $1 \mathrm{E}-1$ with slightly lower titers. For each MODIP, a decrease in DI244 titer was observed after the respective maximum was reached (Fig. 1b). This corresponds to previous findings regarding the decrease of infectious virus titers over cultivation time for wild-type IAV [28]. To analyze the interfering efficacy of biologically active DI244, material harvested at maximum DI244 titers was measured. In addition, vRNA levels (of segment 5 (Seg5), segment 8 (Seg8) and DI244) of the produced virus particles were quantified using real-time RT-qPCR. Surprisingly, maximum DI244 vRNA levels differed strongly for the different MODIPs with highest concentrations achieved for MODIPs 1E-1 and 1E-2 (Fig. 1d). In contrast, maximum vRNA levels of Seg5 and Seg8 were very comparable for all conditions.

To control contamination of the harvested material by defective vRNAs other than DI244 vRNA, a segmentspecific reverse transcription-PCR (segment-specific RTPCR) was performed (Fig. 2). However, no apparent signals indicating deleted vRNAs other than DI244 (Seg1) were observed for any MODIP on any segment.

In summary, the MODIP affected the DI244 production dynamics with earlier accumulation of DIPs at higher MODIPs. All MODIPs resulted in relatively comparable maximum virus titers. In contrast, vRNA levels of DI244 differed strongly, with lower quantities at lower MODIPs. Analysis by segment-specific reverse transcriptase-PCR did not indicate the unwanted accumulation of other vRNAs with deletions, suggesting a clean product.

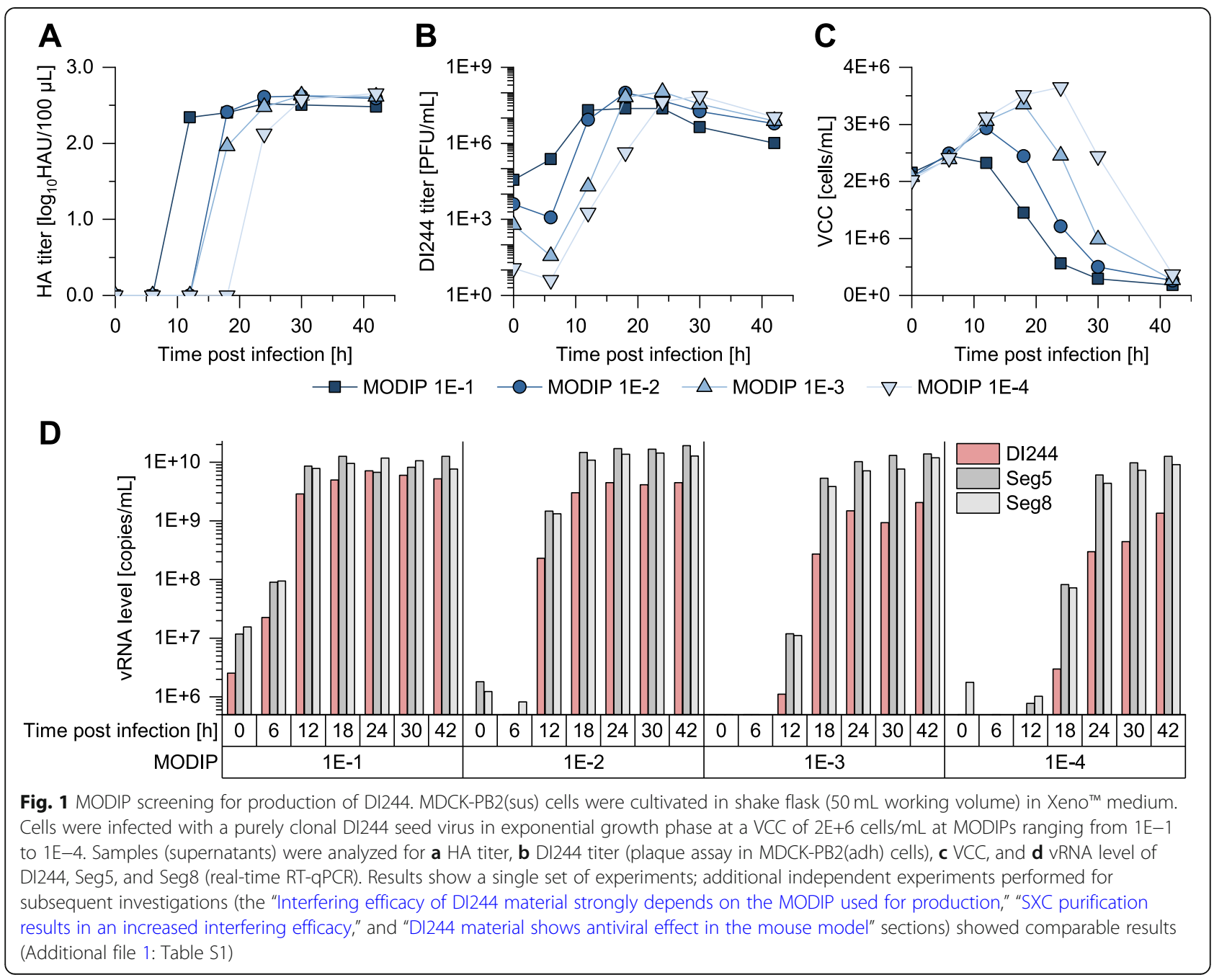



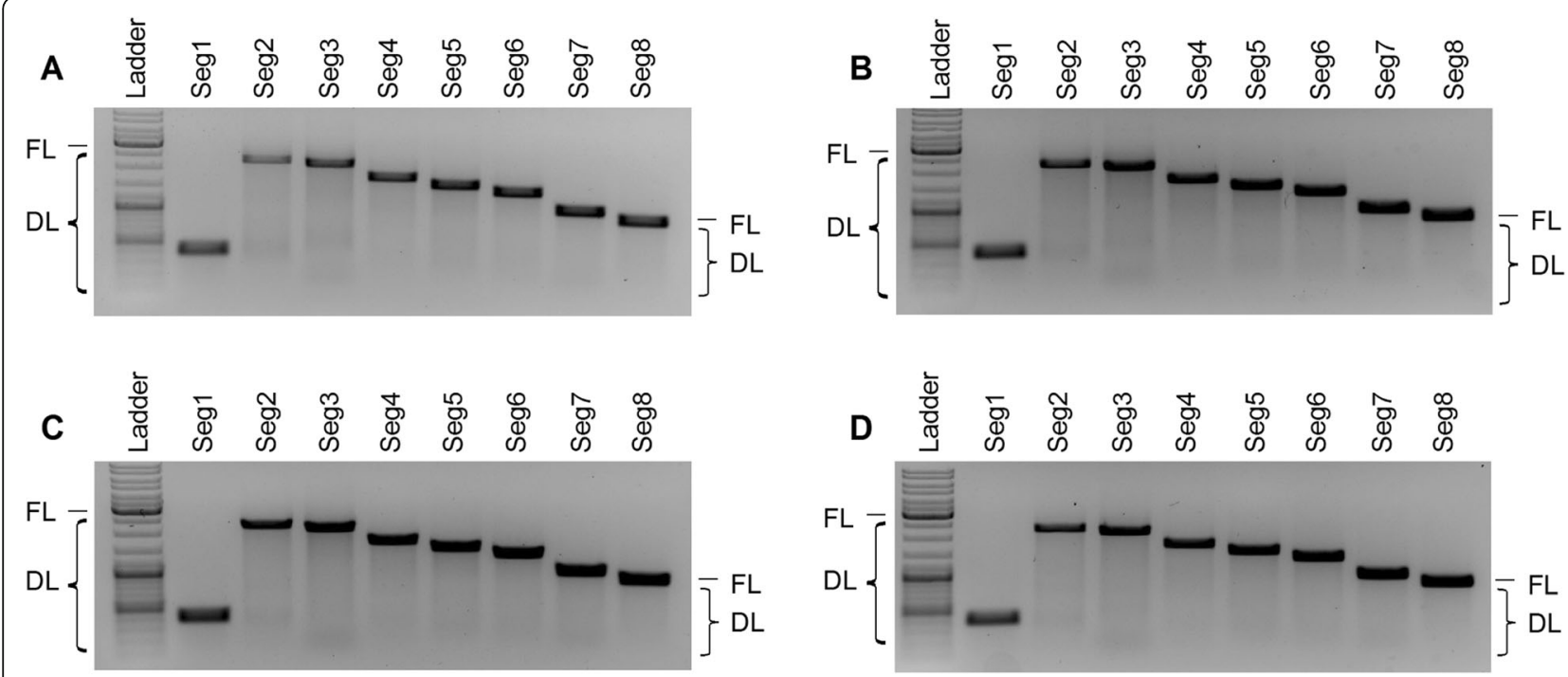

Fig. 2 Purity of DI244 material analyzed for other defective VRNAs. DI244 produced at different MODIPs was analyzed by segment-specific reverse transcriptase-PCR for the presence of short vRNAs in Seg1-8. Results for a MODIP 1E-1, b MODIP 1E-2, c MODIP 1E-3, and d MODIP 1E-4 are shown. Signals corresponding to full-length ( $F L)$ and deleted (DL) vRNAs are indicated ( $F L$ size depends on the analyzed vRNA segment). Ladder: upper thick band $3.0 \mathrm{~kb}$, middle thick band $1.0 \mathrm{~kb}$, lower thick band $0.5 \mathrm{~kb}$

\section{Interfering efficacy of DI244 material strongly depends on} the MODIP used for production

To determine production conditions resulting in material with a high biological efficacy, an in vitro interference assay was utilized. Here, parental adherent MDCK cells were infected with STV and co-infected with the produced DI244 material, and the suppression of STV replication by DI244 assessed by comparing the released virus particles of co-infections with STV infection only. For process monitoring, hemagglutination assay, realtime RT-qPCR, and plaque assay (DI244 titer) were used.

When STV was added at a MOI of 10, addition of DI244 material of any MODIP resulted in a plaque titer reduction of roughly one order of magnitude $(p<0.01$, unpaired two-tailed $t$ test). For cells co-infected with STV at a MOI of 0.01, larger differences between treated and untreated cells were observed $(p<0.05)$. Here, DI244 material produced at a MODIP of $1 \mathrm{E}-2$ resulted in a reduction in the release of infectious STV by more than three orders of magnitude. DI244 material produced at the other MODIPs reduced the release of STV only by less than three (MODIPs $1 \mathrm{E}-1$ and $1 \mathrm{E}-3$ ) or less than two orders of magnitude (MODIP 1E-4). The difference between MODIP $1 \mathrm{E}-2$ and $1 \mathrm{E}-1$ was significant $(p<0.01)$, the difference between MODIP and MODIP $1 \mathrm{E}-2$ and $1 \mathrm{E}-3$ was not $(p=0.12)$. HA titers of samples from the interference assay showed the same trend as plaque titers (Fig. 3a). However, this reduction appeared to be less pronounced, most likely as the release of noninfectious DI244 particles themselves also contributed to the HA titer. Plaque and HA titer normalized to the corresponding $\mathrm{NC}$ are shown in Additional file 1: Fig. S2.

With STV at MOI 10 and addition of different DI244 preparations, all samples showed comparable vRNA levels for Seg5 and Seg8 in the interference assay (Fig. 3b). In contrast, for cells infected at MOI 0.01, strong differences for Seg5 and Seg8 vRNA levels were detected for different DI244 preparations. Here, higher vRNA level was detected for samples with a high virus titer. For all samples (STV MOIs 10 and 0.01), the vRNA levels of Seg5 and Seg8 were similar. In contrast, a lower DI244 vRNA level compared to Seg5 and Seg8 vRNA was observed for the two lowest MODIPs. This is most pronounced for cells infected with STV at a MOI of 10 treated with DI244 produced at MODIP $1 \mathrm{E}-4(p<0.005)$. As the segment-specific RT-PCR did not indicate accumulation of other vRNAs with a deletion (Fig. 2), the interfering effects were mainly caused by DI244.

Taken together, DI244 material produced at different MODIPs showed differences in their interfering efficacies. Material produced at a MODIP of $1 \mathrm{E}-2$ showed the highest activity.

\section{Production in bioreactor scale results in comparable DI244 yields}

In a next step, production of DI244 material in a STR (500 mL) was investigated (Fig. 4). To allow for a comparison with shake flask cultivations, the STR was also inoculated with a VCC $2 \mathrm{E}+6$ cells/mL. After the DO and $\mathrm{pH}$ had stabilized, cells were infected with DI244 at a 

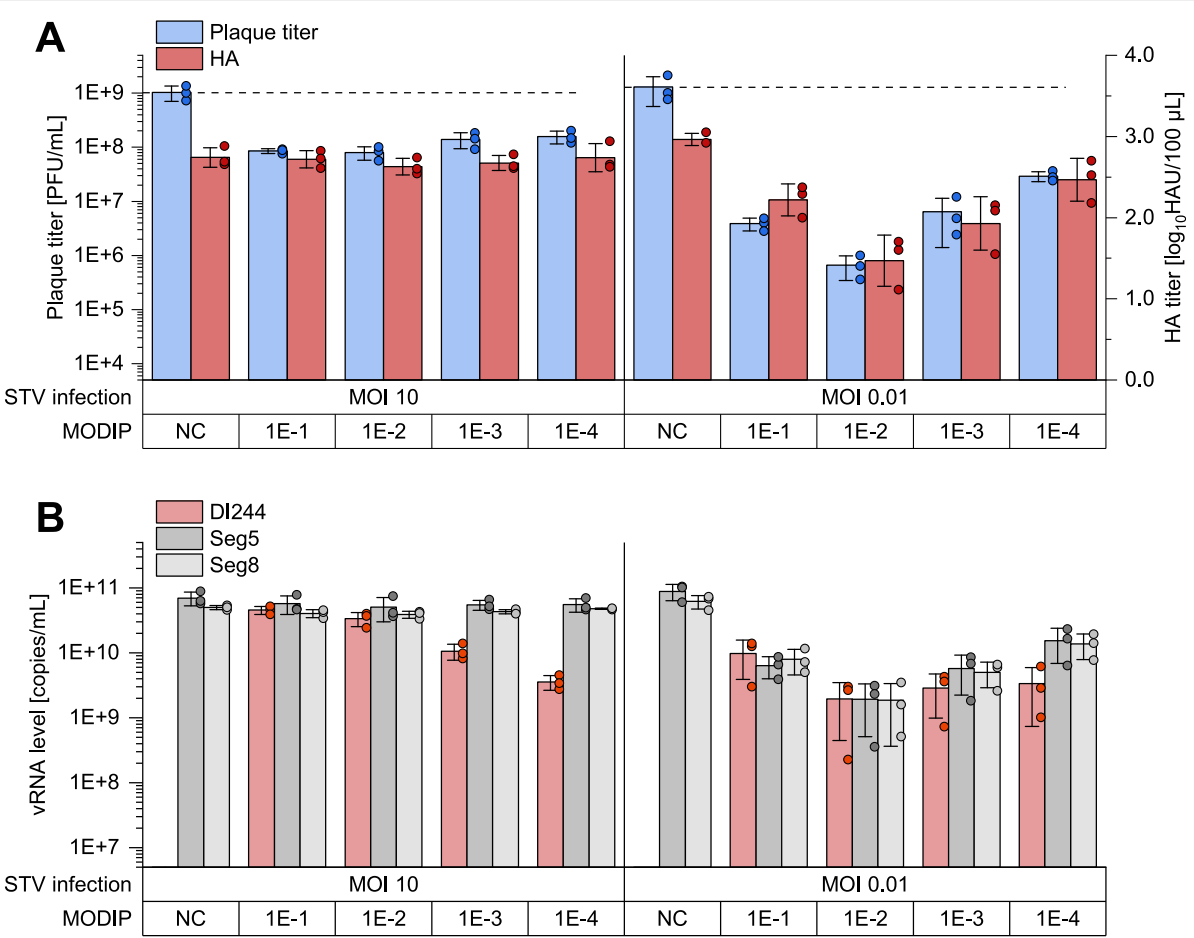

Fig. 3 Interfering efficacy of DI244 material produced at different MODIPs. For the interference assay, parental adherent MDCK cells were infected with STV at MOls of 10, or 0.01 and co-infected with DI244 material $(125 \mu \mathrm{L})$, produced at a MODIP ranging from $1 \mathrm{E}-1$ to $1 \mathrm{E}-4$, or medium as negative control (NC). The supernatant was sampled 16 hpi (STV MOI 10) or 24 hpi (STV MOl 0.01). a Infectious virus titers were quantified by plaque assay (parental adherent MDCK cell). The total amount of virus particles was determined by hemagglutination assay. $\mathbf{b} \vee \mathrm{RNA}$ of DI244, Seg5, and Seg8 were investigated using real-time RT-qPCR. The interference assay was performed in independent experiments $(n=3)$ using one DIP preparation for each MODIP; error bars indicate standard deviation

MODIP of 1E-2. Note that this MODIP resulted in material showing the highest interfering efficacy for the shake flask cultivation (Fig. 3).

Despite the different production scale, aeration conditions, and $\mathrm{pH}$ control, very comparable results were achieved for the dynamics in the HA titer and DI244 vRNA level (Fig. 4a, c) with only minor differences for the DI244 titer and the VCC (Fig. 4b, d). Here, the shake flask cultivation showed a slightly later increase in DI244 titer (Fig. 1b) and an earlier decrease in the VCC (Fig. 1d) compared to the STR. The observed differences might be explained by the improved control of the cultivation conditions in the STR. More specifically, the $\mathrm{pH}$ decreased in a shake flask upon infection, potentially leading to faster cell death and increased virus degradation. In contrast, the $\mathrm{pH}$ was kept constant at 7.6 in the STR.

The DI244 material produced in the STR was then analyzed in the interference assay. Again, a highly comparable interfering efficacy was observed compared to DI244 material produced in the shake flask (Additional file 1: Fig. S3).

In summary, only small differences between a shake flask and a STR cultivation for DI244 production were observed, and large-scale manufacturing of DIPs in STR seems a promising option for future application in antiviral therapy.

\section{SXC purification results in an increased interfering efficacy}

To further increase the interfering efficacy of the DI244 material harvested from shake flasks, it was purified and concentrated by membrane-based SXC. The $0.2 \mu \mathrm{m}$ clarified virus harvest had a dsDNA concentration of $4495 \mathrm{ng} / \mathrm{mL}$. After an enzymatic digestion, the dsDNA concentration of the sample was reduced to $78 \mathrm{ng} / \mathrm{mL}$.

Around $430 \mathrm{~mL}$ of the clarified and digested virus harvest with a total titer of $8.5 \mathrm{E}+5 \mathrm{HAU}$ were injected onto the $100 \mathrm{~cm}^{2}$ SXC filter device with a 1:1 in-line dilution of $16 \%$ PEG-6000, PBS $1 \times$ (Fig. 5a). The first $10 \mathrm{~mL}$ of the elution peak was collected, and this fraction had a total titer of $7.8 \mathrm{E}+5 \mathrm{HAU}$, representing a product yield of $92.3 \%$ and a volumetric concentration factor of around 40-fold. The HA antigen content in the SXC eluate measured by single radial immunodiffusion (SRID) assay was $16.0 \mu \mathrm{g}_{\mathrm{HA}} / \mathrm{mL}$.

The collected eluate had a dsDNA concentration of $192 \mathrm{ng} / \mathrm{mL}$ (total amount $960 \mathrm{ng}$ ), representing a DNA 
A
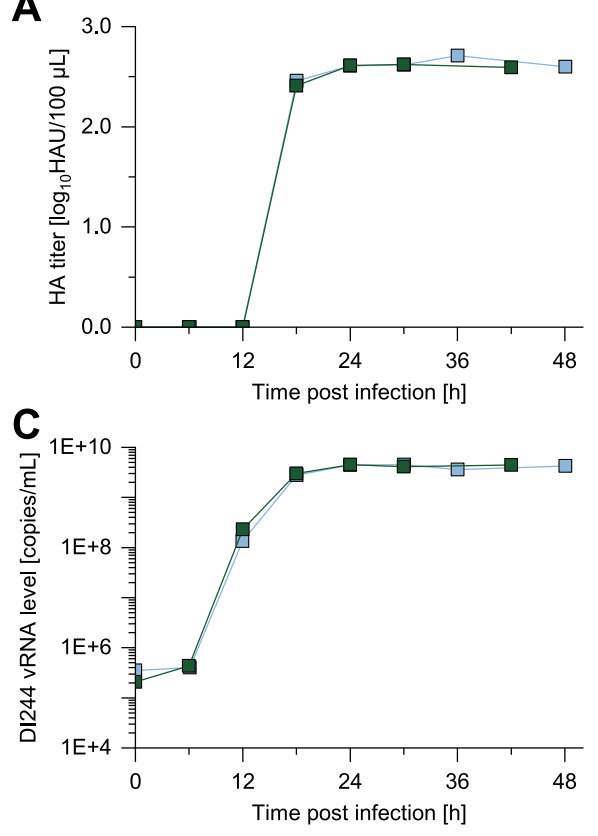

$\square-$ Stirred tank bioreactor $(500 \mathrm{~mL})$

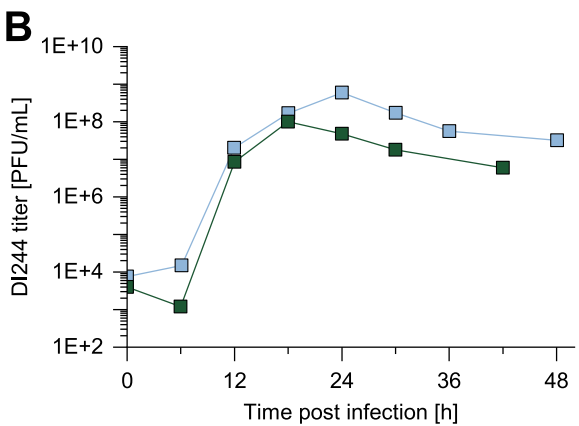

D

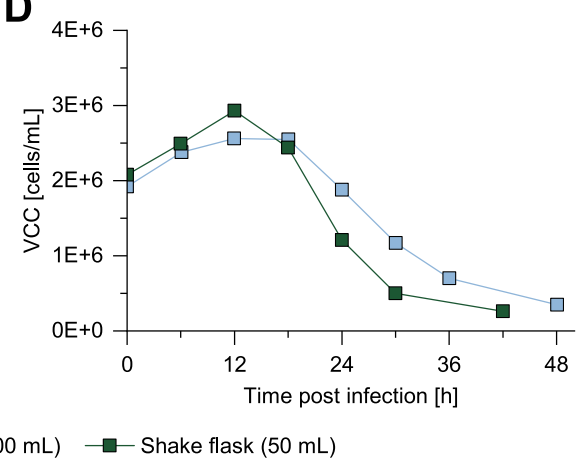

Fig. 4 Comparison of DI244 production in a STR and a shake flask. A STR was inoculated with MDCK-PB2(sus) cells from a shake flask preculture at a VCC of $2 \mathrm{E}+6$ cells $/ \mathrm{mL}$. Cells were infected with purely clonal DI244 seed virus at MODIP 1E-2. a HA titer, b DI244 titer (plaque assay in MDCK-PB2(adh)), c DI244 vRNA level (determined by real-time RT-qPCR), d VCC. For comparison, DI244 production in a shake flask at the same MODIP (Fig. 1) is shown

clearance of $97.1 \%$ for the SXC step alone and $99.95 \%$ with respect to the undigested clarified virus harvest after enzymatic DNA digestion. The total protein concentration in the SXC eluate was $32.5 \mu \mathrm{g} / \mathrm{mL}$ (total amount $325.4 \mu \mathrm{g})$. The total protein clearance of the SXC step was $97.2 \%$ compared to the loaded material $(27.2 \mu \mathrm{g} / \mathrm{mL}$, total amount, 11,696 $\mu \mathrm{g})$.

Next, the SXC eluate was dialyzed with a 300-kDa molecular mass cut-off dialysis tubing, and the collected sample was diluted around 4-fold and sterile-filtered. The dsDNA and HA antigen concentrations in this sample were $48.0 \mathrm{pg}_{\mathrm{dsDNA}} / \mu \mathrm{L}$ and $4.0 \mathrm{ng}_{\mathrm{HA}} / \mu \mathrm{L}$, respectively.

The analytical size exclusion chromatography (SEC) fingerprints of the clarified virus harvest and the SXCpurified virus particles are shown in Fig. 5 (b and c, respectively). Here, light scattering was used to trace virus particles at a retention volume of $7.5 \mathrm{~mL}$. Based on the UV signal from the SEC fingerprints, the virus purity increased from $0.7 \%$ for the clarified virus harvest to $93.0 \%$ for the SXC-purified sample. The particle size distributions of the unpurified virus harvest and the purified sample are shown as determined by differential centrifugal sedimentation (DCS) analysis in Fig. 5 (d and e, respectively). Both samples show a single monodisperse peak with an apparent hydrodynamic size of 74-75 $\mathrm{nm}$.

Next, the biological activity of the purified and 4-fold diluted material was assessed in the interfering assay
(Fig. 6). As expected, a strong increase in the interfering efficacy was observed (Fig. 6) with an approximately 10fold increased reduction in the release of infectious virus particles compared the unpurified material (MOIs 10 and 0.01).

Note that parts of the produced DI244 material were UV-irradiated for $24 \mathrm{~min}$ as a negative control required for animal experiments (the "DI244 material shows antiviral effect in the mouse model" section). For this sample, no DI244 titer could be detected by plaque assay with MDCK-PB2(adh). Moreover, the UV-inactivated DI244 was also tested in the interference assay and no interfering activity was observed (Fig. 6).

In conclusion, SXC was used to purify and concentrate the produced material around 40-fold (10-fold after additional dilution step) with a DI244 yield of $92.3 \%$, host cell DNA clearance of $97.1 \%$ (99.95\% considering the previous nuclease digestion), and total protein clearance of $97.2 \%$. The results of the interference assay demonstrated that efficacy was further increased and highly potent DI244 material was obtained.

DI244 material shows antiviral effect in the mouse model To evaluate the antiviral efficacy of DI244 in vivo, studies in a mouse infection model were performed. The tested DI244 material was produced at MODIP 1E-2 in a shake flask (active) and not purified to allow for a 


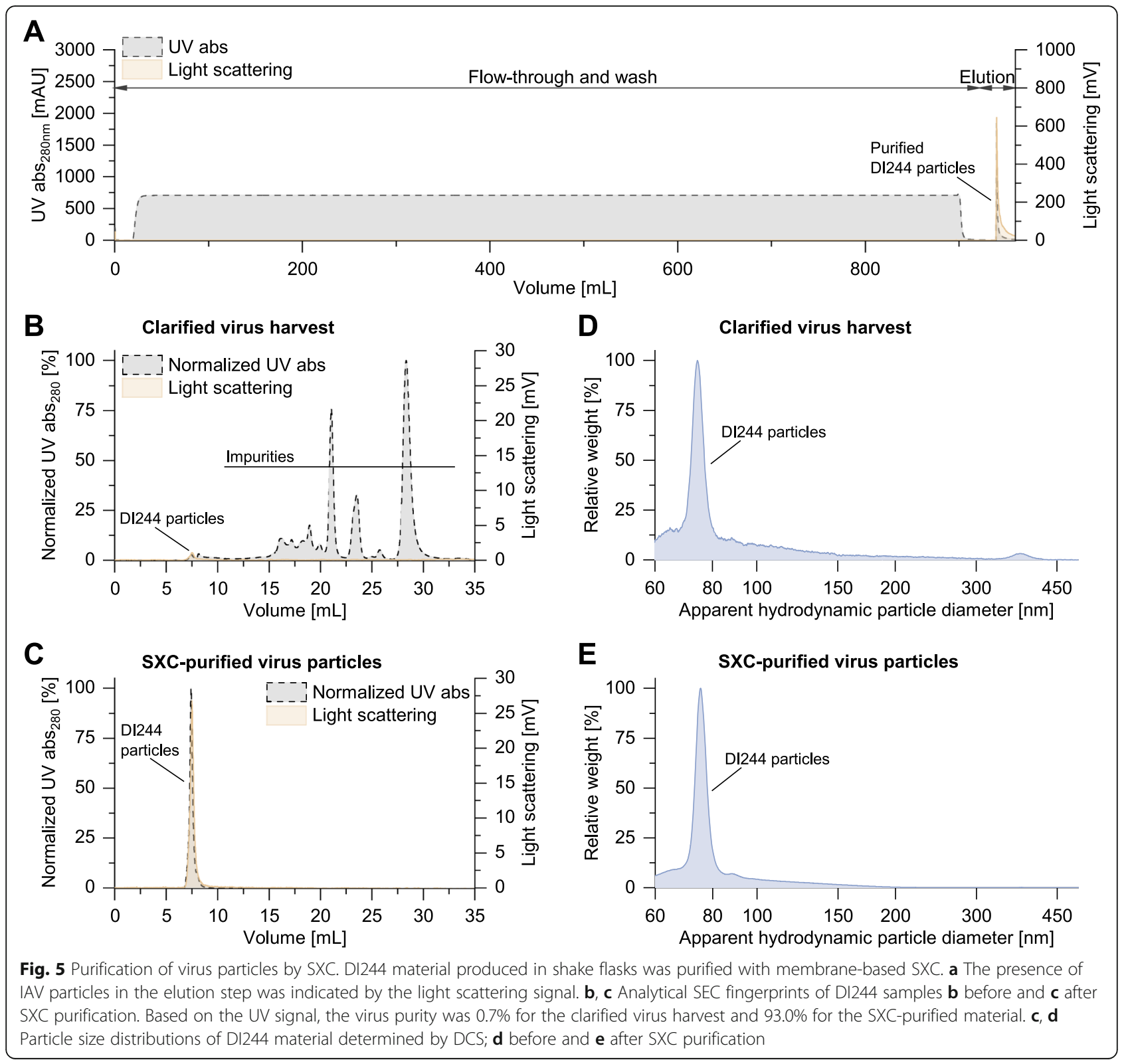

more stringent evaluation of toxicity. Additionally, parts of the material were UV irradiated for $24 \mathrm{~min}$ (inactive) as a control.

First, toxicity of the DI244 was examined (Fig. 7). For this, mice were treated with DI244 material (active, $1.5 \mathrm{E}+6$ PFU per mouse; or inactive) by intranasal application. Neither active DI244 nor inactivated DI244 material caused body weight loss or lethality. These results showed that DI244 alone did not cause any obvious toxic effects. Infections with STV of DBA/2JRj (D2$M \times 1^{-/-}$) mice (lethal dose of 1000 focus forming units (FFU) PR8) resulted in death of all infected mice (Fig. 7). Co-application of active or inactivated DI244 did not rescue D2- $M x 1^{-/-}$mice from these lethal infections (Fig.
7). All mice lost body weight and died between 5 and 7 days post infection.

Next, D2(B6).A2G- $M x 1^{r / r}$ (D2- $\left.M x 1^{r / r}\right)$ mice [29] carrying a functional $M x 1$ allele were infected with the lethal dose of 1000 FFU PR8 STV. All mice lost rapidly body weight and almost all mice died between 6 and 8 days post infection (Fig. 8). Co-application of UV-inactivated DI244 did not rescue infected D2-Mx1 $1^{r / r}$ mice from body weight loss nor lethality (Fig. 8). In strong contrast, $\mathrm{D} 2-M x 1^{r / r}$ mice co-treated with active DI244 $(1.5 \mathrm{E}+6$ PFU per mouse) lost much less body weight and all mice survived the infection (Fig. 8).

In conclusion, treatment of mice with DI244 material did not show any obvious toxic effects. Moreover, co- 


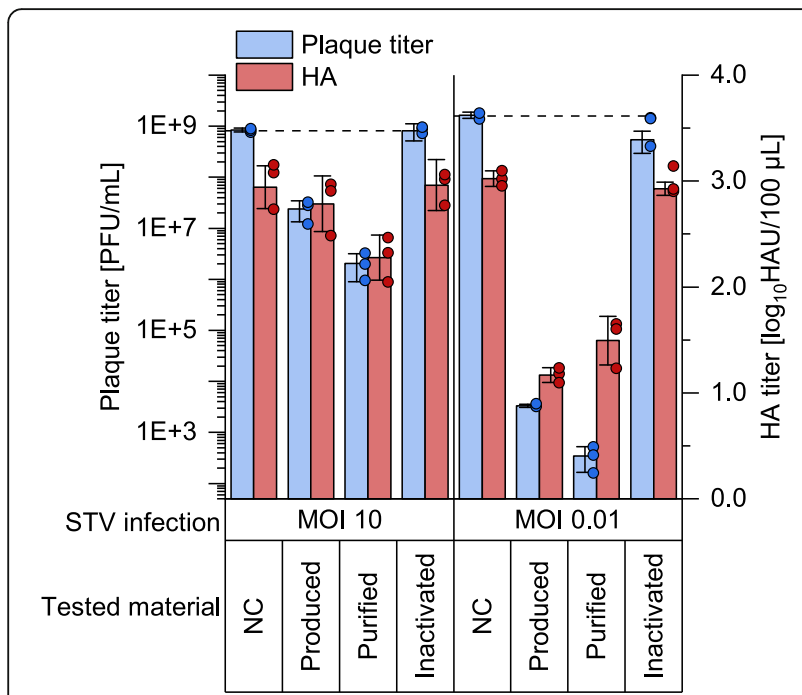

Fig. 6 Interfering efficacy of DI244 material after SXC. Virus titers of the interference assay (see Fig. 3). Tested material was DI244 material produced in shake flask at MODIP 1E- 2, SXC purified material (as shown in Fig. 5), produced material inactivated by UV irradiation for 24 min (inactivated material) or medium as negative control (NC). Inactivated DI244 material was required as a control for animal experiments (Fig. 7). The interference assay was performed in independent experiments $(n=3)$ using one DIP preparation for each tested material. Error bars indicate standard deviation treatment of D2-Mxi ${ }^{r / r}$ mice with active DI244 strongly reduced body weight loss in PR8 STV infected mice and all mice survived whereas control mice treated with inactivated DI244 strongly lost body weight and died. These results clearly demonstrate the antiviral potential of DI244.

\section{Discussion}

In this study, a cell culture-based production process for purely clonal DI244 particles without STV contamination was established. The production process was scaled up from shake flask to a STR with a working volume of $500 \mathrm{~mL}$. The produced material showed high interfering efficacies in an in vitro interference assay, which was further improved after membrane-based SXC purification. Animal trials performed with unclarified shake flask harvests passed toxicity testing. Finally, mice infected with a lethal dose of IAV could be rescued by co-treatment with this DI244 material, demonstrating its antiviral potential.

\section{Advantages of DIPs over currently used small molecule antivirals}

The administration of DIPs to prevent IAV infection might have several benefits. Specifically, DIPs show a fast mode of action, as their protective ability does not depend on the adaptive immune system, which can take up to 2-3 weeks to establish full protection in the case of vaccine administration. Because of their mode of action, DIPs could be used either prophylactically or even

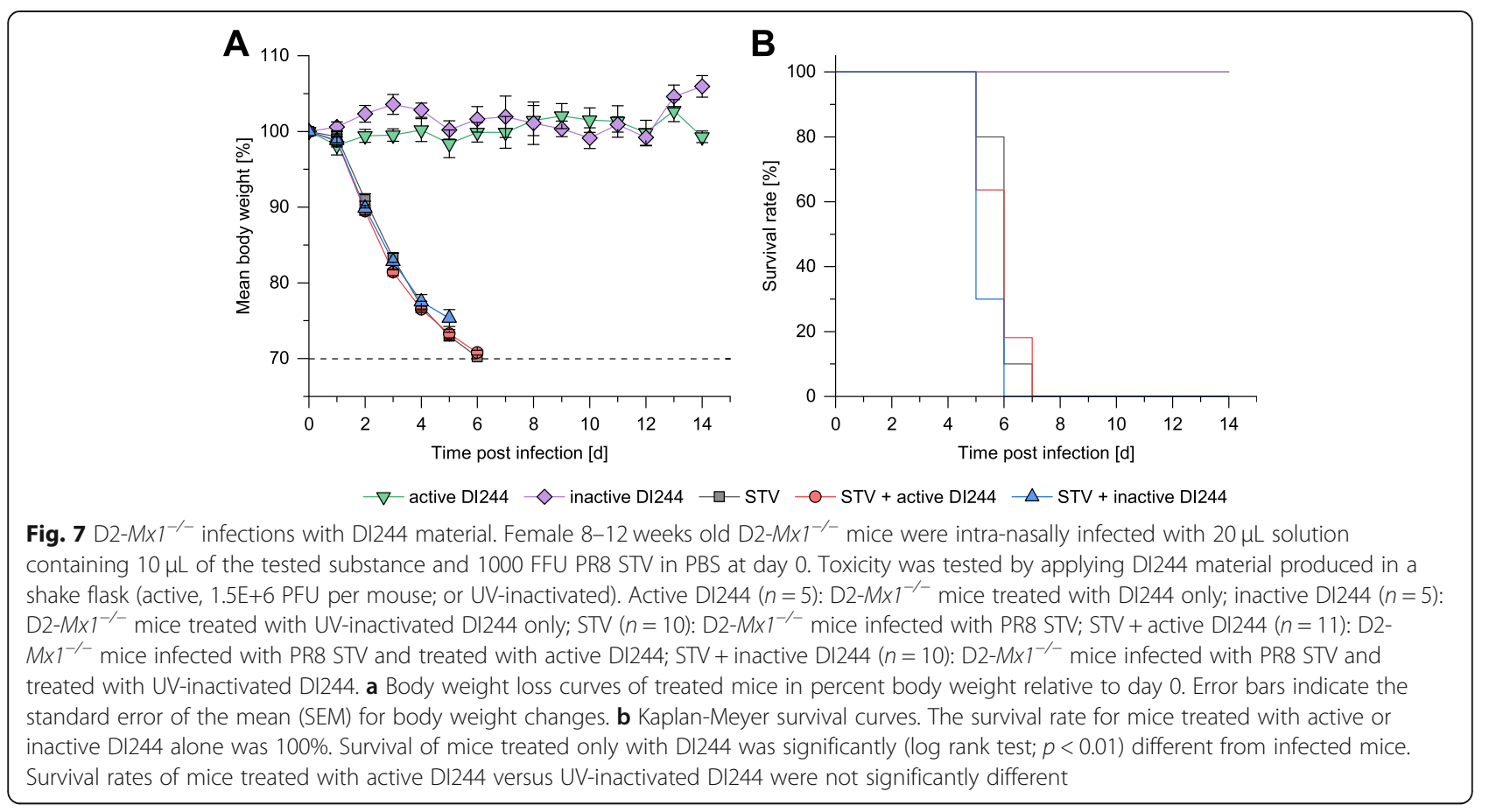



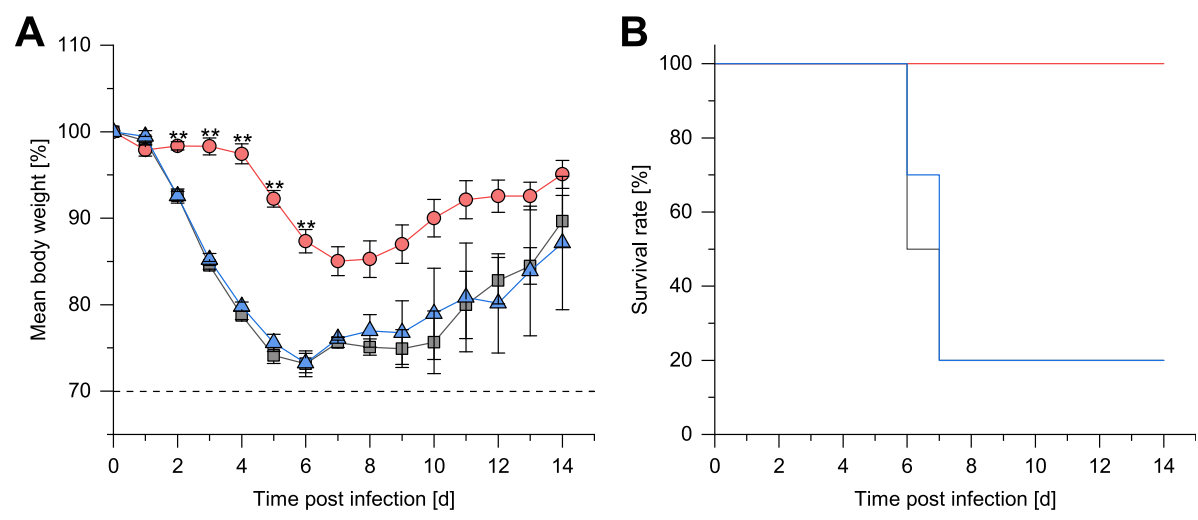

$\square$ STV $-0-\mathrm{STV}+$ active DI244 $\triangle \mathrm{STV}+$ inactive DI244

Fig. $8 \mathrm{D} 2-M \times 7^{r / r}$ infections with DI244 material. Female 8-12 weeks old D2-Mx $7^{r / r}$ mice were intra-nasally infected with $20 \mu \mathrm{L}$ solution containing $10 \mu \mathrm{L}$ of DI244 material produced in shake flask (active, 1.5E+6 PFU per mouse; or UV-inactivated) and 1000 FFU PR8 in PBS at day 0. STV ( $n=10$ ): D2-Mx $7^{r / r}$ mice infected with PR8 STV; STV + active DI244 $(n=12)$ : D2-Mx ${ }^{r / r}$ mice infected with PR8 STV and treated with active DI244; STV + inactive DI244 ( $n=10)$ : D2-MX $7^{r / r}$ mice infected with PR8 STV and treated with UV-inactivated DI244. a Body weight loss curves of treated mice in percent body weight relative to day 0. Error bars indicate the SEM for body weight changes. Statistically significant differences for body weight loss between active DI244 treated group and all other groups were assessed by unpaired two-tailed $t$ test (**: $p<0.001$ ). b Kaplan-Meyer survival curves. The survival rate for mice treated with active DI244 was significantly higher than for all other groups (log rank test; $p<0.0001)$. The survival rate for mice treated with inactive DI244 was not significant different from STV only infected mice $(p=0.63)$

therapeutically [10]. It was shown by Dimmock and Easton that egg-derived and UV-inactivated DI244 material administered 7 days before infection still protected mice from a lethal dose of IAV [25]. Moreover, mice infected with a lethal dose of IAV and treated with DI244 $24 \mathrm{~h}$ after the challenge survived [10]. Partial protection was observed, when DIPs were administered $48 \mathrm{~h}$ after the infection [10]. Furthermore, an antiviral effect of DI244 against a variety of IAV strains was shown [10, 23], including pandemic and highly pathogenic avian strains [30]. This suggests that DIPs, in contrast to currently used vaccines, might have the potential to act universally against IAV [25]. Additionally, an antiviral effect against influenza B and pneumovirus was demonstrated [11,31]. This might be explained by an unspecific protection due to an induction of the innate immune response. Currently, IAV vaccines require annual adaptation to seasonal circulating strains, including accurate prediction, time-consuming generation of a seed virus, and egg or cell culture-based production. In contrast, DIP production in suspension cells would allow manufacturing a high number of doses of an antiviral drug to be better prepared for the next IAV pandemics.

Mice infected with a lethal dose of STV and treated with DI244 did not show symptoms of disease, but still developed an immunity to the pathogenic STV [10]. Here, it was speculated that DIP co-treatment results in the release of non-infectious particles carrying the surface proteins of the pathogenic virus and therefore acts like a live attenuated vaccine [25]. In line with this, it was shown that compared to an untreated control group, DI244 co-treatment did not influence the amount of specific IAV antibodies produced in ferrets. In contrast, reduced antibody titers were detected in oseltamivir treated ferrets [23], emphasizing potential advantages of DIPs over conventional antivirals. Furthermore, resistance against the small molecule antivirals oseltamivir and zanamivir has already been reported [4-6], whereas it is highly unlikely that resistance arises against DIPs: the RNA-dependent RNA polymerase complex (comprising the polymerase subunits $\mathrm{PB} 2, \mathrm{~PB} 1$, and PA proteins) would need to mutate to not recognize and replicate the DI vRNA anymore [25]. However, the same polymerase complex replicates all eight vRNA segments [32-34]. Thus, in addition to mutation of the viral polymerase complex, it would be necessary that mutations of the polymerase recognition sequences of all eight STV vRNA segments arise simultaneously. Only under these circumstances could STV replication without DIP replication take place [25]. The probability that this happens is extremely low and was previously estimated to be around $1 \mathrm{E}-45$ [25]. In conclusion, DIPs with their unique antiviral mechanism are very interesting candidates for prophylactic and therapeutic treatments showing advantages over currently used small molecule antivirals.

\section{Advantages and opportunities of a cell culture-based production processes}

The cell culture-based production process established has several advantages over the previously reported eggbased process [10]. First, it has improved sterility, scalability, and flexibility. Second, it allows for comprehensive monitoring, and tight process control enables a 
reproducible product quality $[19,20,35,36]$. Additionally, genetically modified cells can be used to allow production of purely clonal DIP preparations [26, 27], which completely overcomes the necessity of STV inactivation. Previously, UV light was used to disrupt the STV vRNA [10, 36] by introducing photodimeric lesions [37] or unspecific chain breaks $[38,39]$. Here, it was speculated that larger STV vRNA $(\sim 2.0 \mathrm{~kb})$ should be faster inactivated than the rather small DIP vRNA $(\sim 0.4 \mathrm{~kb})$, as the probability of damaging photoreactions is higher for the STV vRNA [10]. However, it was shown recently that also the DIP vRNA is damaged by UV light, resulting in a decreasing interfering efficacy over UV inactivation time [40]. Moreover, UV inactivation was also used in the current study to generate a negative control, which did not show any interfering efficacy in the interference assay (Fig. 6) or in animal experiments (Figs. 7 and 8). In contrast, the interfering efficacy of the purely produced DIP material was maintained at a very high level. Using our approach, concerns regarding biosafety, i.e., the risk of residual infectious STV due to incomplete inactivation after UV treatment can be avoided.

In principle, the genetically modified MDCK-PB2(sus) may be used universally for cell-culture based production of any IAV Seg1 DIP [26]. The interfering efficacy of a DIP seems to be affected by many factors including genome length, genome sequence, and breaking point [16, 41-43]. Therefore, other DIPs could have a higher interfering efficacy or offer additional advantages over DI244. The generation of genetically modified cell lines expressing another viral protein, e.g., the viral PB1 or PA protein, would also allow production of purely clonal Seg2 or Seg3 DIPs. These segments are of special interest, as deletions in Seg1-3 are most frequently observed $[16,44]$. Here, it was hypothesized that DIPs originated from polymerase genes (Seg1-3) may have advantages over DIPs originating from structural genes (Seg4-8) [22]. For the generation of a purely clonal DIP seed virus, the reverse genetics approach reported earlier represents a universal platform [26].

Lastly, the separation principle of the SXC allows purification of any IAV strain using a single recipe [45]. Therefore, the established platform covering cell line generation, seed virus generation, DIP production, and DIP purification allows to quickly produce a wide range of DIP candidates for testing in an animal model for further use as an antiviral.

\section{The MODIP affected the incorporation of DI244 vRNA in the produced virus particles}

In the present study, Seg5 and Seg8 vRNA levels (considered representative for all STV vRNA segments) were approximately equimolar for each MODIP and each sampling time point. In contrast, DI244 vRNA levels were always lower. This might suggest that Seg5 and Seg8 vRNA were present in every virus particle, whereas the DI244 vRNA was absent in some virus particles. Usually, virus assembly and budding were considered a well-organized process, where each of the eight vRNAs is incorporated in the produced virus particle only once $[46,47]$. This is facilitated by the packaging sequence, present at the $3^{\prime}$ and $5^{\prime}$ end of each vRNA segment [48, 49]. Nevertheless, depending on the strain, up to $20 \%$ of produced viruses do not package at least one vRNA segment [50]. This results in the generation of semiinfectious particles [51]. Naturally occurring virus mutants which completely miss several vRNA segments have also been observed [17].

The MDCK-PB2(sus) cell line used here expressed the viral PB2 protein, encoded by Seg1 vRNA. With the cell line providing the missing $\mathrm{PB} 2$ protein, the virus propagation theoretically does not require an intact Seg1 vRNA. Concurrently, also the deleted Seg1 vRNA from DI244 is not essential for replication. Therefore, the MDCK-PB2(sus) cell line might not only allow production of purely clonal Seg1 DIPs, but also propagation of viruses with only seven segments, completely missing the Seg1 vRNA. This might also explain the lower level of DI244 vRNA in the produced virus particles. Furthermore, DI244 vRNA levels decreased with lower MODIPs. A possible explanation may be that higher MODIPs result in overall more co-infections and therefore a higher probability that all eight segments are present in an infected cell. Here, most produced viruses would incorporate all eight segments. In contrast, in a low MODIP scenario, the likelihood for single-hit infections is increased drastically. Under this condition, cells may occasionally be infected by a virus without DI244 vRNA. Consequentially, those cells could only produce viruses also missing DI244 vRNAs. Additionally, the produced 7-segmented viruses will further accumulate in subsequent infection waves (which are characteristic for low MODIPs).

The lack of DI244 vRNA could also explain the observed differences between plaque and interference assay. More specifically, MODIPs of $1 \mathrm{E}-2$ to $1 \mathrm{E}-4$ resulted in very comparable DI244 titers. In contrast, large differences in the interfering efficacy were observed, where material produced with lower MODIPs induced a less pronounced titer reduction. The DI244 titer was evaluated in a plaque assay with MDCK-PB2(adh) cells. Here, virus particles without incorporated DI244 vRNA could still replicate and would therefore contribute to the DI244 titer. On the other hand, particles without DI244 vRNA would not interfere with STV replication. Therefore, these particles would not contribute to the interfering efficacy determined in the interference assay. Consequentially, material produced at a MODIP of $1 \mathrm{E}$ 
-2 , showing the highest DI244 vRNA level (for MODIP $1 \mathrm{E}-2$ to $1 \mathrm{E}-4)$ resulted in the most pronounced titer reduction. DIP material produced at a MODIP of $1 \mathrm{E}-1$ showed comparable vRNA levels, but lower DI244 titers. A possible explanation could be that the interfering efficacy of this material is lower due to a faster onset of DI244 production, resulting in an earlier onset of degradation of biologically active virus particles and a reduced number of virions carrying DI244 vRNA to the cells. Another explanation for the observed reduction of DI244 and HA titers of material produced at a MODIP of $1 \mathrm{E}-1$ might be a self-interference of DIPs at high MODIPs, as reported by other groups [52, 53].

The mechanism proposed here, where DI vRNAs might not be efficiently incorporated in the produced virus particles, when produced with a complementing cell line, would have implications for the DIP production process. The risk that high amounts of virus particles without any therapeutic effect might be produced, especially at lower MODIPs (usually used for cell culturebased viral vaccine production) is of particular importance. Therefore, optimization of the MODIP seems crucial for the establishment of a production process as it might drastically affect the quality of DIP harvests.

\section{Purification of DI244 harvests}

The product yield of the SXC purification step measured by hemagglutination assay was $92.3 \%$. This is consistent with previous results for downstream processing of IAV [54], as was the concentration of the HA antigen in the SXC eluate of this work $\left(16.0 \mu \mathrm{g}_{\mathrm{HA}} / \mathrm{mL}\right)$. The clearance of host cell DNA was $97.1 \%$, and adding a DNA digestion step prior to SXC increased the DNA clearance to $99.95 \%$. The total protein clearance was $97.2 \%$, which is also consistent with previously reported data [54].

The dsDNA concentration of the clarified virus harvest in this work was $4495 \mathrm{ng} / \mathrm{mL}$ compared to around $4300 \mathrm{ng} / \mathrm{mL}$ from a similar process for IAV production using SMIF8 chemically defined medium [54]. With a dsDNA concentration of $192 \mathrm{ng} / \mathrm{mL}$ in the eluate, the estimated dsDNA concentration of this material was $0.05 \mathrm{ng} / \mu \mathrm{L}$ and therefore about 100 -fold lower than that of the unpurified material $(4.6 \mathrm{ng} / \mu \mathrm{L})$ administered to mice for toxicity testing. A further reduction in the amount of DNA can be achieved, for instance with optimizations in cell culture that could reduce the total burden of DNA introduced into the purification train, a longer DNA enzymatic digestion, or with additional polishing steps, such as pseudo-affinity chromatography with sulfated membrane adsorbers [55] or ion exchange chromatography.

Another interesting topic would be the separation of active DI244 particles from 7-segmented viruses, discussed in the previous section. The difference in the nucleotide cargo between the two virus populations might result in an isoelectric point difference that could be exploited for their chromatographic separation by isoelectric focusing $[56,57]$ or even ion exchange. These options provide alternatives for future work.

\section{Evaluation of DI244 interfering efficacy in animal and in vitro models}

Administration of DI244 alone did not induce body weight loss nor result in a decreased survival rate and therefore did not appear to be highly toxic. To further elaborate potential toxicity of DI224 administration, histopathology or blood chemistry of mice could be performed [58]. Co-treatment with DI244 did not show a positive impact on body weight loss or survival rate in

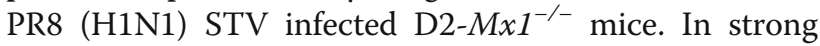
contrast, infected D2-Mx1 $1^{r / r}$ mice treated with DI244 showed a reduced body weight loss and all animals survived the infection.

MX1 represents an interferon-induced protein, which binds to the ribonucleo-protein particles of IAV and thereby inhibits viral replication $[59,60]$. The protective activity of MX1 against IAV was originally discovered in A2G mice that carry a wild-type $M x 1$ allele $[59,61]$. However, most laboratory strains, including the most commonly used strain, C57BL/6, do not carry a functional $M x 1$ allele $[59,62]$. These common laboratory mice express $M x 1$ transcripts with a deletion or nonsense mutation in the open reading frame resulting in a non-functional protein $[59,62]$. The wild type functional $M \times 1$ allele has been transferred from A2G to C57BL/6 mice [63] to generate strain B6.A2G- $M x 1^{r / r}\left(\mathrm{~B} 6-M x 1^{r / r}\right)$. B6-Mx1 ${ }^{r / r}$ mice are per se highly resistant against infections with IAV $[63,64]$. Since these mice scarcely show clinical symptoms and mortality, they do not allow testing of anti-viral treatments.

Humans carry a functional $M X 1$ allele, but are still susceptible to IAV infections. Therefore, we generated a mouse model that better mimics the human situation. We introduced the wild type $M x 1$ allele into DBA/2 mice, resulting in mouse strain D2-Mx1 $1^{r / r}$, which now expresses a fully functional MX1 protein. In contrast to B6- $M x 1^{r / r}$ mice, D2- $M x 1^{r / r}$ mice are still highly susceptible to IAV infections. However, after pretreatment with interferon, D2- $M x 1^{r / r}$ become resistant to IAV infections demonstrating that in these mice a fully functional and protective MX1 protein can be produced. We previously [29] have described the detailed characterization of the D2- $M x 1^{r / r}$ model. Thus, our D2- $M x 1^{r / r}$ IAV infection model which has been used here for the DI244 functional studies represents an ideal system that better reflects the human situation and allows testing of antiviral treatments in the context of a fully functional $M x 1$ allele. 
The infection experiments with the different mouse models demonstrate the importance of a functional innate immune response for the antiviral effect of DIPs in vivo. Here, we hypothesize that DI244 in mice inhibits viral replication, as we have demonstrated in our in vitro studies, but in addition induces interferon, which subsequently activates the highly protective functional $M x 1$ gene in D2-Mx $1^{r / r}$ mice. Both effects will lead to lower viral loads in the lung, the rapid induction of a potent innate immune response, and protection from a lethal outcome. Virus-specific antibodies and cytotoxic $\mathrm{T}$ cells typically start to appear at 7 days post infection and are fully mounted after 14 days. Thus, an adaptive immune response would come too late in a primary infection to protect against a severe outcome during the first week. We thus conclude that in this model, DI244 does not primarily have a vaccination effect. However, mice treated with DIPs will survive the infection, and in these mice, an adaptive immune response will be mounted. Such an adaptive immune response will protect against a secondary infection [10]. Therefore, DIP treatment will not only be beneficial for protection against severe disease in the early phase of a primary IAV infection but also contribute to mounting a long-lasting protective immunity. Here, it would also be of interest to investigate the impact of the time of DIP application (e.g., a few days before or after challenge virus administration).

The in vitro interference assay used here was carried out with MDCK cells, which express a canine MX1 lacking activity against the human IAV strain PR8 [65]. Furthermore, trypsin added to the medium used in the interference assay degrades the secreted interferon [66]. Therefore, the interfering effects observed in the in vitro assay are most likely explained by DIPs interfering with the replication of the STV, rather than induction of the innate immune response. In order to understand better the contribution of the innate immune response to the interference of DIPs in vitro, additional experiments are necessary. For example, the interference assay could be carried out with a human cell line carrying a functional MX1 (e.g., A549 or HEK293 cells). Additionally, to avoid interferon degradation by trypsin, the virus strain A/ WSN/33, which does not rely on trypsin addition for its propagation [67], could be used and is topic of ongoing research.

Finally, it would be desirable to conduct infection experiments in ferrets, as they are susceptible to human IAV and air-borne virus transmission [68-70]. In a next step, infection experiments in macaques could be carried out, as their clinical symptoms closely resemble those found in humans [71]. Trials in both animals would represent a significant step towards studies in humans to demonstrate the protective effect of DIPs and the use of DIP preparations as antiviral drugs. Here, it would also be of interest to investigate the impact of the time of DIP application (e.g., a few days before or after challenge virus administration).

\section{Conclusion}

In this proof-of-principle study, we established a cell culture-based production and purification platform for generation of purely clonal Seg1 DIP material, which does not require inactivation. The proposed platform could be used to quickly produce new DIP candidates for testing in an animal model. In addition, it allows fast scale up for manufacturing of a high number of doses if required. The produced DI244 material showed strong antiviral effects in animal experiments. As far as we are aware, this is the first time purely clonal DIP material was produced at bioreactor scale. Additionally, it was the first time purely clonal DIP material that does not require UV inactivation positively demonstrated its antiviral potential in an animal model.

\section{Methods \\ Cells and viruses}

For production of non-infectious DIPs (DI244 containing a large internal deletion on Seg1 vRNA), a suspension MDCK cell line adapted to growth in a chemically defined Xeno ${ }^{\text {Tu }}$ medium was used [72]. Next, this suspension cell line was genetically modified by retroviral transduction as described before for adherent MDCK cells [26], to stably express the viral PB2 protein and a puromycin resistance gene as selective marker. Briefly, a cell suspension of $1.0 \mathrm{E}+6$ cells $/ \mathrm{mL}$ was seeded in shake flasks in $10 \mathrm{~mL}$ chemically defined Xeno medium. Simultaneously, $10 \mathrm{~mL}$ of supernatant containing MLV particles was added per flask. In parallel, non-transduced suspension cells were supplemented with $10 \mathrm{~mL}$ Dulbecco's Modified Eagle Medium containing 10\% fetal bovine serum (FBS, Gibco), penicillin (100 IU/mL), and streptomycin $(100 \mu \mathrm{g} / \mathrm{mL})$ to maintain similar medium condition. Next day, cells were centrifuged at $300 \times g$ for $5 \mathrm{~min}$ and resuspended with $20 \mathrm{~mL}$ fresh chemically defined medium. Two days post transduction, cell suspension was counted and supplemented with $0.5 \mu \mathrm{g} / \mathrm{mL}$ puromycin. In the following, the generated cell line is called MDCK-PB2(sus).

MDCK-PB2(sus) cells were cultivated either in (i) a shake flask with $50 \mathrm{~mL}$ working volume $(125 \mathrm{~mL}$ baffled polycarbonate Erlenmeyer Flask, Thermo Fisher Scientific, $4116-0125$ ) at $37^{\circ} \mathrm{C}, 5 \% \mathrm{CO}_{2}$, and $185 \mathrm{rpm}$ (Multitron Pro, Infors HT; $50 \mathrm{~mm}$ shaking orbit) or (ii) a STR with a working volume of $500 \mathrm{~mL}$ (DASGIP ${ }^{\circ}$ Parallel Bioreactor System, Eppendorf AG, 76DG04CCBB) at $37^{\circ} \mathrm{C}, \geq 40 \% \mathrm{O}_{2}, \mathrm{pH} 7.6$, and $150 \mathrm{rpm}$ (marine impeller). For cultivation of parental adherent MDCK cells (ECAC C, No. 84121903) or adherent MDCK cells expressing 
PB2 [26], hereafter called MDCK-PB2(adh), Glasgow minimum essential medium (GMEM) (Thermo Fisher Scientific, \#22100093) containing 1\% peptone and 10\% fetal bovine serum (cultivation medium) was used $\left(37^{\circ} \mathrm{C}, 5 \% \mathrm{CO}_{2}\right)$. For MDCK-PB2(adh), $1.5 \mu \mathrm{g} / \mathrm{mL}$ puromycin (Thermo Fisher Scientific, \#A1113803) were added to the cultivation medium. For seed train generation of suspension cells, $0.5 \mu \mathrm{g} / \mathrm{mL}$ puromycin was added. All infection studies were performed without puromycin addition.

Purely clonal DI244 virus was generated using an eight-plasmid DNA transfection system [73], MDCKPB2(adh), and $293 \mathrm{~T}$ cells expressing PB2 [26]. The virus was expanded in MDCK-PB2(sus) cells to yield a seed virus with a DI244 titer of $1.01 \mathrm{E}+8 \mathrm{DIPs} / \mathrm{mL}$ (assayed in MDCK-PB2(adh) cells, see the "Virus quantification assays" section). For STV infections, the H1N1 influenza virus A/Puerto Rico/8/34 (PR8) from the Robert Koch Institute Germany $\left(1.1 \mathrm{E}+9 \quad \mathrm{TCID}_{50} / \mathrm{mL}\right)$ was used. Multiplicity of infection (MOI) was calculated based on the fifty-percent tissue culture infection dose $\left(\mathrm{TCID}_{50}\right)$ titer [74]. For infection of MDCK-PB2 cells, MODIP was calculated based on the DI244 titer.

\section{Cell culture-based production of DI244}

MDCK-PB2(sus), cultivated in shake flasks in exponential growth phase, were centrifuged $(300 \times g, 5 \mathrm{~min}$, room temperature) to allow for media exchange. Next, cells were transferred to an STR or shake flask at a VCC of $2 \mathrm{E}+6$ cells $/ \mathrm{mL}$ (with fresh media). For subsequent infection, trypsin (Thermo Fisher Scientific, \#27250-018) was added $(20 \mathrm{U} / \mathrm{mL}$ final activity) and DI244 seed virus at the indicated MODIP. The VCC was measured with a cell counter (Vi-CELL XR, Beckman Coulter, \#731050) with a relative standard deviation (RSD) of $\leq 6 \%$. For some analytical procedures described below, a small volume of cell suspension was centrifuged $(3000 \times g, 10 \mathrm{~min}$, $4{ }^{\circ} \mathrm{C}$ ) and aliquots of the cell-free supernatants stored at $-80^{\circ} \mathrm{C}$ until further analysis.

\section{UV-irradiation}

UV irradiation was utilized to inactivate the produced DI244 material (required as a control for animal experiments). Treatments were carried out in a laminar hood (Thermo Fisher Scientific, Safe 2020) to ensure sterility. For this, the material was transferred into an open tray $\left(250 \mathrm{~cm}^{2}\right.$ surface area) for direct exposure using the UV lamps in the side walls of the laminar hood for $24 \mathrm{~min}$. The tray was shaken continuously using a mixer (Duomax 1030, 543-32205-00 Heidolph, Schwabach, Germany) ensuring a thin film layer (approximately 2 $\mathrm{mm}$ ) and a homogenous inactivation. Afterwards, parental adherent MDCK cells were infected with purely clonal DI244 harvests and inactivated DI244 material.
For both DI244 preparations, no STV replication could be detected.

\section{Downstream processing of DI244 material}

To increase its interfering efficacy and to reduce the level of contaminating protein and DNA, the harvested DI244 material was purified by membrane-based SXC.

\section{Sample preparation before capture chromatography}

DI244 material produced in shake flasks was clarified by a series of successive microfiltration steps using regenerated cellulose filter discs with a diameter of 5 $\mathrm{cm}$ and pore sizes of $1.0 \mu \mathrm{m}, 0.45 \mu \mathrm{m}$, and $0.2 \mu \mathrm{m}$ (GE Healthcare; Uppsala, Sweden) fitted to a vacuumoperated reusable bottle top device (\# 528199-325; VWR; Radnor, USA). The sample volume after the final $0.2 \mu \mathrm{m}$ filtration step is named "clarified virus harvest" hereafter.

The clarified virus harvest was treated with an unspecific nuclease (Denarase, named "Denarase" hereafter, \#2DN100KU99; Sartorius Stedim Biotech; Göttingen, Germany) to digest the host cell DNA. For this, the clarified virus harvest was supplemented with magnesium chloride (\#M8266-1KG; Sigma-Aldrich Chemie $\mathrm{GmbH}$; Munich, Germany) to a final concentration of 2 $\mathrm{mM}$ and $50 \mathrm{U} / \mathrm{mL}$ of Denarase. The sample was incubated ( $4.5 \mathrm{~h}$, room temperature) under mixing with a magnetic stirrer at $250 \mathrm{rpm}$.

\section{Chromatographic purification}

For all chromatography experiments, an ÄKTA Pure 25 (GE Healthcare; Uppsala, Sweden) liquid chromatography system was used at room temperature and controlled by the software UNICORN v6.3 was used. The UV absorbance was monitored at $280 \mathrm{~nm}$ and virus particles were monitored with a NICOMPTM 380 (Particle Sizing Systems; Santa Barbara, USA) submicron particle analyzer at $632.8 \mathrm{~nm}$.

Membrane-based SXC [54] was used for virus purification. The SXC device consisted of a stack of $1.0 \mu \mathrm{m}$ regenerated cellulose membranes (\#10410014; GE Healthcare; Uppsala, Sweden) (20 layers; $100 \mathrm{~cm}^{2}$ total surface area with a column volume of $1 \mathrm{~mL}$ ) fitted into a stainless steel filter housing $(25 \mathrm{~mm})$. The pressure limit at the inlet of the column was set to $2.00 \mathrm{MPa}$. The flow rates used were $5-10 \mathrm{~mL} / \mathrm{min}$.

SXC purification was performed in bind-elute mode. In short, (A) Equilibration: after a washing step of 10 column volumes of water, the column was equilibrated with 10 column volumes of $8 \%$ PEG-6000, PBS. (B) Sample injection: the Denarase-treated sample was mixed inline in a 1:1 ratio with a stock solution of PEG-6000 (\#81260-5KG; Sigma-Aldrich Chemie GmbH; Munich, Germany) and PBS to achieve a final concentration of 
8\% PEG-6000. After sample injection $(10 \mathrm{~mL} / \mathrm{min})$, a wash step $(10 \mathrm{~mL} / \mathrm{min})$ followed with $8 \%$ PEG-6000, PBS until baseline UV absorbance was achieved. (C) Elution: virus particles were eluted using 20 column volumes of PBS $(5 \mathrm{~mL} / \mathrm{min})$.

An analytical SEC with a packed-bed Superdex 200 Increase 10/300 GL (\# 17517501; GE Healthcare; Uppsala, Sweden) column was conducted. The injection volumes were $100-500 \mu \mathrm{L}$ with a flow rate of $0.75 \mathrm{~mL} / \mathrm{min}$.

\section{Formulation}

The SXC eluate was dialyzed against PBS (overnight, $4{ }^{\circ} \mathrm{C}$ ) with a $300-\mathrm{kDa}$ molecular mass cut-off dialysis tubing $(16 \times 10 \mathrm{~mm}$, width $\times$ diameter $)$ made of a cellulose ester (\#GZ-02890-77; Spectra Por) with a sample to buffer ratio of 1:1000. First, the collected sample was spiked with sorbitol to a final concentration of $4 \%$. Next, the sample was sterile-filtered $(0.2 \mu \mathrm{m}$ cellulose acetate syringe filter (\#16534--.------K; Sartorius Stedim Biotech; Göttingen, Germany). The final DI244 material was stored at $-80^{\circ} \mathrm{C}$ until evaluation in in vitro assays or animal experiments.

\section{Mouse experiments Mouse model}

D2- $M x 1^{-/-}$mice carrying a non-functional $M x 1$ gene were obtained from Janvier (France). D2- $M x 1^{r / r}$ carrying a functional $M x 1$ gene was generated in our laboratory by backcrossing DBA/2JRj mice for 10 generations onto congenic B6.A2G-Mx1 $1^{r / r}$ mice as described previously [29]. All mice were maintained under specific pathogen free conditions at the Central Animal Facilities of the HZI, Braunschweig.

\section{Infection of mice}

The production of a PR8 STV used for mouse infections and titration of FFU was performed as described previously $[58,75]$. Mice (female, $8-12$ weeks old) were anesthetized by intra-peritoneal injection of ketaminexylazine solution $(5 \mathrm{mg} / \mathrm{mL}$ ketamine, WDT, Garbsen; 1 $\mathrm{mg} / \mathrm{ml}$ xylazine, CP Pharma, Burgdorf; in sterile 0.9\% $\mathrm{NaCl}, \mathrm{WDT}$, Garbsen) with a dose adjusted to the individual body weight $(200 \mu \mathrm{L} / 20 \mathrm{~g}$ body weight). Mice were treated with $20 \mu \mathrm{L}$ PBS solution containing $10 \mu \mathrm{L}$ of DI244 material and 1000 FFU of PR8 by intranasal application. Subsequently, body weight and survival were monitored for 14 days. In addition to mice that were found dead, mice with a body weight loss of more than $30 \%$ of the starting body weight were euthanized and recorded as dead.

\section{Interference assay}

The produced DI244 material was evaluated using an interference assay [17]. Here, to assess the interfering efficacy, the reduction in the release of infectious virions upon co-infection with STV and DI244 is compared to an infection with STV only. For infection, parental adherent MDCK cells (1E+6 cells per well) cultivated in 6well plates were used. Cells were washed with phosphate buffered saline (PBS). Next, cells were either infected with only STV (PR8) at a MOI of 10 or 0.001 or coinfected with STV and a fixed volume of $125 \mu \mathrm{L}$ of DI244 material. Infections were conducted in $250 \mu \mathrm{L}$ infection medium (GMEM containing $1 \%$ peptone and 5 $\mathrm{U} / \mathrm{mL}$ trypsin). After $1 \mathrm{~h}$ of incubation $\left(37^{\circ} \mathrm{C}, 5 \% \mathrm{CO}_{2}\right)$, the inoculum was removed and cells were washed with PBS. Next, $2 \mathrm{~mL}$ of infection medium were added and cells were further incubated $\left(37^{\circ} \mathrm{C}, 5 \% \mathrm{CO}_{2}\right)$. Infections were incubated for $16 \mathrm{~h}$ or $24 \mathrm{~h}$, depending on the MOI of STV added (10 or 0.001 , respectively). Supernatants were centrifuged $\left(3000 \times g, 10 \mathrm{~min}, 4{ }^{\circ} \mathrm{C}\right)$, and aliquots were stored at $-80^{\circ} \mathrm{C}$ until further analysis.

\section{Virus quantification assays}

For quantification of the total virus particle titer, a hemagglutination assay was used, as described in [76]. Here, the HA titer can be either reported as $\log _{10} \mathrm{HA}$ units $/ 100 \mu \mathrm{L}\left(\log _{10} \mathrm{HAU} / 100 \mu \mathrm{L}\right)$ or as HAU/100 $\mu \mathrm{L}$ and the total amount of HAU in a virus preparation can be calculated. The RSD for technical triplicates was s 13.3\%. For quantification of infectious virus titers, a plaque assay was used. For this, parental adherent MDCK cells in 6-well plates were utilized. Cells were washed with PBS. Next, each $250 \mu \mathrm{L}$ of a serial 10 -fold dilution series (of each sample) were used to infect the cells for $1 \mathrm{~h}\left(37^{\circ} \mathrm{C}, 5 \% \mathrm{CO}_{2}\right)$. The supernatant was removed and cells were overlaid with $1 \%$ agar in infection medium (GMEM containing 1\% peptone and $5 \mathrm{U} / \mathrm{mL}$ trypsin). Cells were then incubated for 4 days $\left(37^{\circ} \mathrm{C}, 5 \%\right.$ $\mathrm{CO}_{2}$ ) until staining. Ice-cold methanol was used for fixation, and cells were stained using a $0.2 \%$ crystal violet solution. Finally, light microscopy was used to determine the plaque forming units per $\mathrm{mL}$. For quantification of samples containing only DI244, the same plaque assay was used but with MDCK-PB2(adh) cells. Statistical differences were determined by unpaired two-tailed $t$ test. The RSD of technical duplicates was $\leq 43.8 \%$.

Additionally, the HA antigen content in the purified DI244 material (see Section "Downstream processing of DI244 material") was quantified by a SRID assay as reported before [54]. The purified virus particles were dialyzed overnight at $4{ }^{\circ} \mathrm{C}$ using a $300-\mathrm{kDa}$ molecular mass cut-off dialysis tubing $(16 \times 10 \mathrm{~mm}$, width $\times$ diameter $)$ made of a cellulose ester (\#GZ-02890-77; Spectra Por) with a sample to buffer ratio of 1:1000. Dialyzed samples were spiked with sucrose as a cryoprotectant to a final concentration of $1 \%$ and lyophilized afterwards. The lyophilized samples were resuspended by adjusting the 
HA content of the samples (around 6200 HAU per replicate) to the HA content of an in-house reference standard as previously reported by [77]. The assay was setup in a $1 \%$ agarose gel with a $7 \times 7$ diffusion matrix containing $64 \mu \mathrm{g}$ anti-A/PR/8/34 H1N1 serum per $\mathrm{mL}$ (\#03/242; NIBSC; Hertfordshire, England). Measurements are reported in $\mu \mathrm{g}_{\mathrm{HA}}$ per $\mathrm{mL}$. The RSD of technical duplicates was $\leq 4.9 \%$.

\section{PCR measurements}

To analyze the genomic vRNA of virus particles, PCRbased methods were used. The vRNA in the supernatant samples was purified using the NucleoSpin ${ }^{\circ}$ RNA virus kit (Macherey-Nagel, 740,956) according to manufacturer's instructions. To identify vRNAs containing a deletion (indicating the presence of DIPs), a segmentspecific RT-PCR was used (section "Segment-specific RT-PCR"). For quantification of Seg5, Seg8, and the deleted DI244 vRNA, a real-time RT-qPCR was used (section "Real-time RT-qPCR").

\section{Segment-specific RT-PCR}

For reverse transcription (RT)-PCR, a previously described method was used [78]. In short, RT of RNA samples (isolated vRNAs of released virus particles) was carried out as a single reaction using a universal primer that hybridizes to the conserved 3' region of all eight genome segments [79]. For the following PCR, individual segment specific primers were used. Amplified PCR products were visualized by agarose gel electrophoresis, and investigated for the presence of short PCR products, indicating DI vRNAs.

\section{Real-time $R T-q P C R$}

For real-time RT-qPCR, a method described previously [80] was used that allows gene-specific quantification of individual IAV vRNA segments. In vitro generation of reference standards, RT, real-time qPCR, and absolute quantification of vRNA levels are described elsewhere [17, 81]. To allow quantification of DI244 vRNA, a primer that binds across the junction region of DI244 was used [36]. The RSD of technical quadruplicates was $\leq 52.5 \%$.

\section{Differential centrifugal sedimentation}

DCS was used to determine the particle size distribution of DI244 material before and after purification, as reported previously [82] . For this, a CPS DC24000 UHR disc centrifuge (CPS Instruments Inc.; Los Angeles, USA) operated at $24,000 \mathrm{rpm}$ with a $4-16 \%(\mathrm{~m} / \mathrm{v}) \mathrm{su}-$ crose gradient in PBS was used. The gradient was formed by nine $1.6 \mathrm{~mL}$ steps with a different sucrose concentration each $(16 \%, 14.5 \%, 13 \%, 11.5 \%, 10 \%, 8.5 \%$, $7 \%, 5.5 \%$, and $4 \%$ sucrose $(\mathrm{m} / \mathrm{v}))$ resulting in a total volume of $14.4 \mathrm{~mL}$. For gradient quality evaluation, a 239 $\mathrm{nm}$ particle standard (0.3-0.5\% solid content, polyvinyl chloride, CPS Instruments Inc.; Los Angeles, USA) was injected directly after gradient generation. After $10 \mathrm{~min}$ of equilibration, another injection of a 239-nm particle standard followed for measurement calibration. Finally, $100 \mu \mathrm{L}$ of the undiluted sample was injected for the size distribution measurements. Densities were $1.072 \mathrm{~g} / \mathrm{cm}^{3}$ for the gradient buffer, $1.385 \mathrm{~g} / \mathrm{cm}^{3}$ for the calibration particles, and $1.180 \mathrm{~g} / \mathrm{cm}^{3}$ for IAV. The particle size distribution is shown as normalized weight average (in percent) against the apparent hydrodynamic diameter.

\section{Quantitation of total protein and host cell dsDNA}

Total protein was measured using a Bradford BioRad assay (\#5000006; BioRad Laboratories; Hercules, USA). The calibration curve was made with bovine serum albumin (\#A3912; Sigma-Aldrich Chemie GmbH; Munich, Germany) in the range of $5-40 \mu \mathrm{g} / \mathrm{mL}$ and had a limit of detection of $0.4 \mu \mathrm{g} / \mathrm{mL}$. The RSD of technical triplicates was $\leq 6.3 \%$.

The concentration of host cell dsDNA was estimated with a Quant-iTTM PicoGreen ${ }^{\circ}$ assay (\# P7581; Life Technologies GmbH; Darmstadt, Germany). The standard curve was made with $\lambda$ DNA (\#D1501; Promega; Madison, USA) in the range of $4-250 \mathrm{ng} / \mathrm{mL}$ and had a limit of detection of $1.6 \mathrm{ng} / \mathrm{mL}$. The RSD of technical duplicates was $\leq 2.1 \%$.

\section{Supplementary Information}

The online version contains supplementary material available at https://doi. org/10.1186/s12915-021-01020-5.

Additional file 1: Figure S1. Maximum specific growth rates of suspension MDCK cells. Figure S2. Interfering efficacy of DI244 material produced at different MODIPs. Figure S3. Interfering efficacy of DI244 material produced at MODIP $1 \mathrm{E}-2$ in different cultivation vessels. Table S1. Overview on DI244 titers reported for shake flask cultivations in chapter 3.

\section{Acknowledgements}

The authors would like to thank Nancy Wynserski, Claudia Best, and Anja Bastian for their excellent technical assistance. We thank the animal caretakers at the Central Animal Facilities of the HZI for maintaining the mice and Karin Lammert and Jennifer Fricke for excellent technical assistance. The authors would like to thank Lars Pelz for fruitful discussions. B6.A2G-Mxir/r mice were kindly provided by Peter Stäheli, University of Freiburg, Germany. The authors greatly appreciate the contribution of Shanghai BioEngine SciTech and Prof. Tan from the East China University of Science and Technology for providing the $\mathrm{Xeno}^{\mathrm{TM}}$ medium.

\section{Authors' contributions}

Conceptualization, M.D.H., Y.G., K.S., S.P., S.Y.K., and U.R.; methodology, M.D.H., P.A., and P.M.; investigation, M.D.H., P.A., P.M., and K.S.; writing-original draft, M.D.H., P.M., K.S., and S.Y.K.; writing-review and editing, M.D.H., P.A., P.M., Y.G., M.W., S.P., K.S., S.Y.K., and U.R.; supervision, Y.G., M.W., S.P., K.S., S.Y.K., and U.R.; project administration, M.D.H and S.Y.K.; funding acquisition, K.S. and U.R. The authors read and approved the final manuscript.

\section{Funding}

The present study was funded by intramural grants from the HelmholtzAssociation (Program Infection and Immunity) and the Defense Advanced Research Projects Agency (https://www.darpa.mil/program/intercept) and 
INTERCEPT program under Cooperative Agreement W911NF-17-2-0012) Open Access funding enabled and organized by Projekt DEAL.

\section{Availability of data and materials}

The datasets generated and analyzed during the current study are available in the Mendeley repository [83]. Data generated and analyzed during this study are also included in this published article and its additional files. The Supplementary Material for this article is attached.

Cell lines and mouse strains will be made available upon request.

\section{Declarations}

\section{Ethics approval and consent to participate}

All experiments in mice were approved by an external committee according to the national guidelines of the animal welfare law in Germany (BGBI. I S. 1206, 1313 and BGBI. I S. 1934). The protocol used in these experiments has been reviewed by an ethics committee and approved by the relevant authority, the "Niedersächsisches Landesamt für Verbraucherschutz und Lebensmittelsicherheit, Oldenburg, Germany" (Permit Number: 33.19.4250204-18/2922)

\section{Consent for publication}

Not applicable.

\section{Competing interests}

The authors declare no competing interests.

\section{Author details}

'Otto-von-Guericke-University Magdeburg, Chair of Bioprocess Engineering, Magdeburg, Germany. ${ }^{2}$ German Primate Center-Leibniz Institute for Primate Research, Infection Biology Unit, Göttingen, Germany. ${ }^{3}$ University Göttingen, Faculty of Biology and Psychology, Göttingen, Germany. ${ }^{4}$ Max Planck Institute for Dynamics of Complex Technical Systems, Bioprocess Engineering, Magdeburg, Germany. ${ }^{5}$ Helmholtz Centre for Infection Research, Department of Infection Genetics, Braunschweig, Germany. ${ }^{6}$ University of Veterinary Medicine Hannover, Hannover, Germany. ${ }^{7}$ University of Tennessee Health Science Center, Department of Microbiology, Immunology and Biochemistry, Memphis, TN, USA

\section{Received: 20 August 2020 Accepted: 1 April 2021}

Published online: 03 May 202

\section{References}

1. Iuliano AD, Roguski KM, Chang HH, Muscatello DJ, Palekar R, Tempia S, et al. Estimates of global seasonal influenza-associated respiratory mortality: a modelling study. Lancet. 2018;391(10127):1285-300. https:/doi.org/10.1016/ S0140-6736(17)33293-2

2. Taubenberger JK, Reid AH, Fanning TG. The 1918 influenza virus: a killer comes into view. Virology. 2000;274(2):241-5. https://doi.org/10.1006/viro.2 000.0495 .

3. Johnson NP, Mueller J. Updating the accounts: global mortality of the 19181920 "Spanish" influenza pandemic. Bull Hist Med. 2002;76(1):105-15. https://doi.org/10.1353/bhm.2002.0022.

4. Colman PM. New antivirals and drug resistance. Annu Rev Biochem. 2009; 78(1):95-118. https://doi.org/10.1146/annurev.biochem.78.082207.084029.

5. Oxford JS. Antivirals for the treatment and prevention of epidemic and pandemic influenza. Influenza Other Respir Viruses. 2007;1(1):27-34. https:// doi.org/10.1111/j.1750-2659.2006.00006.x.

6. Smith J, Dutkowski R, Ward P. Antivirals for influenza in healthy adults. Lancet. 2006;367(9522):1571; author reply 3. https://doi.org/10.1016/S01406736(06)68683-2.

7. Han J, Perez J, Schafer A, Cheng H, Peet N, Rong L, et al. Influenza virus: small molecule therapeutics and mechanisms of antiviral resistance. Cur Med Chem. 2018;25(38):5115-27. https://doi.org/10.2174/09298673246661 70920165926

8. Lackenby A, Besselaar TG, Daniels RS, Fry A, Gregory V, Gubareva LV, et al. Global update on the susceptibility of human influenza viruses to neuraminidase inhibitors and status of novel antivirals, 2016-2017. Antivir Res. 2018;157:38-46. https://doi.org/10.1016/j.antiviral.2018.07.001.

9. Dimmock NJ, Beck S, McLain L. Protection of mice from lethal influenza: evidence that defective interfering virus modulates the immune response and not virus multiplication. J Gen Virol. 1986;67(Pt 5):839-50. https://doi. org/10.1099/0022-1317-67-5-839.

10. Dimmock NJ, Rainsford EW, Scott PD, Marriott AC. Influenza virus protecting RNA: an effective prophylactic and therapeutic antiviral. J Virol. 2008;82(17): 8570-8. https://doi.org/10.1128/JVI.00743-08

11. Scott PD, Meng B, Marriott AC, Easton AJ, Dimmock NJ. Defective interfering influenza A virus protects in vivo against disease caused by a heterologous influenza B virus. J Gen Virol. 2011;92(Pt 9):2122-32. https://doi.org/10.1099/ vir.0.034132-0.

12. Scott PD, Meng B, Marriott AC, Easton AJ, Dimmock NJ. Defective interfering influenza virus confers only short-lived protection against influenza virus disease: evidence for a role for adaptive immunity in DI virus-mediated protection in vivo. Vaccine. 2011;29(38):6584-91. https://doi.org/10.1016/j.va ccine.2011.06.114

13. Smith CM, Scott PD, O'Callaghan C, Easton AJ, Dimmock NJ. A defective interfering influenza RNA inhibits infectious influenza virus replication in human respiratory tract cells: a potential new human antiviral. Viruses. 2016; 8(8):237. https://doi.org/10.3390/v8080237. PMID: 27556481; PMCID: PMC4997599.

14. Lazzarini RA, Keene JD, Schubert M. The origins of defective interfering particles of the negative-strand RNA viruses. Cell. 1981;26(2 Pt 2):145-54. https://doi.org/10.1016/0092-8674(81)90298-1.

15. Perrault J. Origin and replication of defective interfering particles. Curr Top Microbiol Immunol. 1981;93:151-207. https://doi.org/10.1007/978-3-64268123-3_7.

16. Nayak DP, Chambers TM, Akkina RK. Defective-interfering (DI) RNAs of influenza viruses: origin, structure, expression, and interference. Curr Top Microbiol Immunol. 1985;114:103-51. https://doi.org/10.1007/978-3-64270227-3_3.

17. Kupke SY, Riedel D, Frensing T, Zmora P, Reichl U. A novel type of influenza A virus-derived defective interfering particle with nucleotide substitutions in its genome. J Virol. 2019;93:e01786-18. https://doi.org/10.1128/JVI.01786-18.

18. Huang AS, Baltimore D. Defective viral particles and viral disease processes. Nature. 1970;226(5243):325-7. https://doi.org/10.1038/226325a0.

19. Frensing T, Pflugmacher A, Bachmann M, Peschel B, Reichl U. Impact of defective interfering particles on virus replication and antiviral host response in cell culture-based influenza vaccine production. Appl Microbiol Biotechnol. 2014;98(21):8999-9008. https://doi.org/10.1007/s00253-014-5933-y.

20. Tapia F, Laske T, Wasik MA, Rammhold M, Genzel Y, Reichl U. Production of defective interfering particles of influenza a virus in parallel continuous cultures at two residence times-insights from qPCR measurements and viral dynamics modeling. Front Bioeng Biotechnol. 2019;7:275. https://doi.org/1 0.3389/fbioe.2019.00275

21. Dimmock NJ, Easton AJ. Defective interfering influenza virus RNAs: time to reevaluate their clinical potential as broad-spectrum antivirals? J Virol. 2014; 88(10):5217-27. https://doi.org/10.1128/JVI.03193-13.

22. Laske T, Heldt FS, Hoffmann H, Frensing T, Reichl U. Modeling the intracellular replication of influenza A virus in the presence of defective interfering RNAs. Virus Res. 2016;213:90-9. https://doi.org/10.1016/j.virusres.2015.11.016.

23. Dimmock NJ, Dove BK, Meng B, Scott PD, Taylor I, Cheung L, et al. Comparison of the protection of ferrets against pandemic 2009 influenza A virus (H1N1) by 244 DI influenza virus and oseltamivir. Antivir Res. 2012; 96(3):376-85. https://doi.org/10.1016/j.antiviral.2012.09.017.

24. Mann A, Marriott AC, Balasingam S, Lambkin R, Oxford JS, Dimmock NJ. Interfering vaccine (defective interfering influenza A virus) protects ferrets from influenza, and allows them to develop solid immunity to reinfection. Vaccine. 2006;24(20):4290-6. https://doi.org/10.1016/j.vaccine.2006.03.004.

25. Dimmock NJ, Easton AJ. Cloned defective interfering influenza RNA and a possible pan-specific treatment of respiratory virus diseases. Viruses. 2015; 7(7):3768-88. https://doi.org/10.3390/v7072796.

26. Bdeir N, Arora P, Gartner S, Hoffmann M, Reichl U, Pohlmann S, et al. A system for production of defective interfering particles in the absence of infectious influenza A virus. PLoS One. 2019;14(3):e0212757. https://doi.org/1 0.1371/journal.pone.0212757.

27. Yamagata Y, Muramoto Y, Miyamoto S, Shindo K, Nakano M, Noda T. Generation of a purely clonal defective interfering influenza virus. Microbiol Immunol. 2019;63(5):164-71. https://doi.org/10.1111/1348-0421.12681.

28. Genzel Y, Dietzsch C, Rapp E, Schwarzer J, Reichl U. MDCK and Vero cells for influenza virus vaccine production: a one-to-one comparison up to lab-scale bioreactor cultivation. Appl Microbiol Biotechnol. 2010;88(2):461-75. https:// doi.org/10.1007/s00253-010-2742-9. 
29. Shin DL, Hatesuer B, Bergmann S, Nedelko T, Schughart K. Protection from severe influenza virus infections in mice carrying the Mx1 influenza virus resistance gene strongly depends on genetic background. J Virol. 2015; 89(19):9998-10009. https://doi.org/10.1128/JVI.01305-15.

30. Zhao H, To KKW, Chu H, Ding Q, Zhao X, Li C, et al. Dual-functional peptide with defective interfering genes effectively protects mice against avian and seasonal influenza. Nat Commun. 2018;9(1):2358. https://doi.org/10.1038/ s41467-018-04792-7.

31. Easton AJ, Scott PD, Edworthy NL, Meng B, Marriott AC, Dimmock NJ. A novel broad-spectrum treatment for respiratory virus infections: influenzabased defective interfering virus provides protection against pneumovirus infection in vivo. Vaccine. 2011;29(15):2777-84. https://doi.org/10.1016/j.va ccine.2011.01.102

32. Cianci C, Tiley L, Krystal M. Differential activation of the influenza virus polymerase via template RNA binding. J Virol. 1995;69(7):3995-9. https://doi. org/10.1128/JVI.69.7.3995-3999.1995.

33. Hagen M, Chung TD, Butcher JA, Krystal M. Recombinant influenza virus polymerase: requirement of both $5^{\prime}$ and $3^{\prime}$ viral ends for endonuclease activity. J Virol. 1994;68(3):1509-15. https://doi.org/10.1128/JVl.68.3.1509-1515.1994.

34. Tiley LS, Hagen M, Matthews JT, Krystal M. Sequence-specific binding of the influenza virus RNA polymerase to sequences located at the $5^{\prime}$ ends of the viral RNAs. J Virol. 1994;68(8):5108-16. https://doi.org/10.1128/JVI.68.8.51085116.1994.

35. Swick A, Baltes A, Yin J. Visualizing infection spread: dual-color fluorescent reporting of virus-host interactions. Biotechnol Bioeng. 2014;111(6):1200-9. https://doi.org/10.1002/bit.25170

36. Wasik MA, Eichwald L, Genzel Y, Reichl U. Cell culture-based production of defective interfering particles for influenza antiviral therapy. Appl Microbiol Biotechnol. 2018;102(3):1167-77. https://doi.org/10.1007/s00253-017-8660-3.

37. Remsen JF, Miller N, Cerutti PA. Photohydration of uridine in the RNA of coliphage R17. II. The relationship between ultraviolet inactivation and uridine photohydration. Proc Natl Acad Sci U S A. 1970;65(2):460-6. https:// doi.org/10.1073/pnas.65.2.460.

38. Coahran DR, Buzzell A, Lauffer MA. The effect of ultraviolet irradiation on nucleic acid isolated from tobacco mosaic virus. Biochim Biophys Acta. 1962;55(5):755-67. https://doi.org/10.1016/0006-3002(62)90854-5.

39. Jericevic Z, Kucan I, Chambers RW. Photochemical cleavage of phosphodiester bonds in oligoribonucleotides. Biochemistry. 1982;21(25): 6563-7. https://doi.org/10.1021/bi00268a037.

40. Hein MD, Kollmus H, Marichal-Gallardo P, Puttker S, Benndorf D, Genzel Y, et al. OP7, a novel influenza A virus defective interfering particle: production, purification, and animal experiments demonstrating antiviral potential. Appl Microbiol Biotechnol. 2021;105(1):129-46. https://doi.org/10.1 007/s00253-020-11029-5

41. Duhaut SD, Dimmock NJ. Defective segment 1 RNAs that interfere with production of infectious influenza A virus require at least 150 nucleotides of 5' sequence: evidence from a plasmid-driven system. J Gen Virol. 2002;83(Pt 2):403-11. https://doi.org/10.1099/0022-1317-83-2-403.

42. Duhaut SD, McCauley JW. Defective RNAs inhibit the assembly of influenza virus genome segments in a segment-specific manner. Virology. 1996; 216(2):326-37. https://doi.org/10.1006/viro.1996.0068.

43. Odagiri T, Tashiro M. Segment-specific noncoding sequences of the influenza virus genome RNA are involved in the specific competition between defective interfering RNA and its progenitor RNA segment at the virion assembly step. J Virol. 1997;71(3):2138-45. https://doi.org/10.1128/JVI. 71.3.2138-2145.1997.

44. Davis AR, Nayak DP. Sequence relationships among defective interfering influenza viral RNAs. Proc Natl Acad Sci U S A. 1979;76(7):3092-6. https://doi. org/10.1073/pnas.76.7.3092.

45. Marichal-Gallardo P, Fortuna AR, Genzel Y, Wolff MW, Reichl U. Purifying viruses with a sheet of paper: single-use steric exclusion chromatography as a capture platform for vaccine candidates. In: Kamen A, Mukhopadhyay T, Garcon N, Lutsch C, eds., Conference Proceedings: Vaccine Technology VII, June 17-22, 2018, Mont Tremblant, 2018. http://dc.engconfintl.org/vt_vii/12 8. Accessed 18 Dec 2019

46. Chou YY, Vafabakhsh R, Doganay S, Gao Q, Ha T, Palese P. One influenza virus particle packages eight unique viral RNAs as shown by FISH analysis. Proc Natl Acad Sci U S A. 2012;109(23):9101-6. https://doi.org/10.1073/pnas.1206069109.

47. Noda T, Kawaoka Y. Packaging of influenza virus genome: robustness of selection. Proc Natl Acad Sci U S A. 2012;109(23):8797-8. https://doi.org/10.1 073/pnas.1206736109.
48. Fujii Y, Goto H, Watanabe T, Yoshida T, Kawaoka Y. Selective incorporation of influenza virus RNA segments into virions. Proc Natl Acad Sci U S A. 2003; 100(4):2002-7. https://doi.org/10.1073/pnas.0437772100.

49. Hutchinson EC, von Kirchbach JC, Gog JR, Digard P. Genome packaging in influenza A virus. J Gen Virol. 2010;91(Pt 2):313-28. https://doi.org/10.1099/ vir.0.017608-0.

50. Nakatsu S, Sagara H, Sakai-Tagawa Y, Sugaya N, Noda T, Kawaoka Y. Complete and incomplete genome packaging of influenza $A$ and $B$ viruses. mBio. 2016;7(5):e01248-16. https://doi.org/10.1128/mBio.01248-16.

51. Brooke CB, Ince WL, Wrammert J, Ahmed R, Wilson PC, Bennink JR, et al. Most influenza A virions fail to express at least one essential viral protein. J Virol. 2013;87(6):3155-62. https://doi.org/10.1128/JVI.02284-12.

52. Sekellick MJ, Marcus PI. Viral interference by defective particles of vesicular stomatitis virus measured in individual cells. Virology. 1980;104(1):247-52. https://doi.org/10.1016/0042-6822(80)90385-2.

53. Stauffer Thompson KA, Rempala GA, Yin J. Multiple-hit inhibition of infection by defective interfering particles. J Gen Virol. 2009;90(Pt 4):888-99. https://doi.org/10.1099/vir.0.005249-0.

54. Marichal-Gallardo P, Pieler MM, Wolff MW, Reichl U. Steric exclusion chromatography for purification of cell culture-derived influenza A virus using regenerated cellulose membranes and polyethylene glycol. J Chromatogr A. 2017;1483:110-9. https://doi.org/10.1016/j.chroma.201 6.12.076.

55. Fortuna AR, Taft F, Villain L, Wolff MW, Reichl U. Optimization of cell culturederived influenza A virus particles purification using sulfated cellulose membrane adsorbers. Eng Life Sci. 2018;18(1):29-39. https://doi.org/10.1002/ elsc.201700108.

56. Leisi R, Wolfisberg R, Nowak T, Caliaro O, Hemmerle A, Roth NJ, et al. Impact of the isoelectric point of model parvoviruses on viral retention in anionexchange chromatography. Biotechnol Bioeng. 2021;118(1):116-29. https:// doi.org/10.1002/bit.27555.

57. Michen B, Graule T. Isoelectric points of viruses. J Appl Microbiol. 2010; 109(2):388-97. https://doi.org/10.1111/j.1365-2672.2010.04663.x.

58. Wilk $\mathrm{E}$, Schughart $\mathrm{K}$. The mouse as model system to study host-pathogen interactions in influenza A infections. Curr Protoc Mouse Biol. 2012;2(2):177205. https://doi.org/10.1002/9780470942390.mo110173.

59. Haller O, Arnheiter H, Pavlovic J, Staeheli P. The discovery of the antiviral resistance gene $\mathrm{mx}$ : a story of great ideas, great failures, and some success. Ann Rev Virol. 2018;5(1):33-51. https://doi.org/10.1146/annurev-virology-092 917-043525.

60. Gao S, von der Malsburg A, Dick A, Faelber K, Schroder GF, Haller O, et al. Structure of myxovirus resistance protein a reveals intra- and intermolecular domain interactions required for the antiviral function. Immunity. 2011;35(4): 514-25. https://doi.org/10.1016/j.immuni.2011.07.012.

61. Lindenmann J, Lance CA, Hobson D. The resistance of A2G mice to myxoviruses. J Immunol. 1963;90:942

62. Staeheli P, Grob R, Meier E, Sutcliffe JG, Haller O. Influenza virussusceptible mice carry Mx genes with a large deletion or a nonsense mutation. Mol Cell Biol. 1988:8(10):4518-23. https://doi.org/10.1128/MCB. 8.10.4518

63. Koerner I, Kochs G, Kalinke U, Weiss S, Staeheli P. Protective role of beta interferon in host defense against influenza A virus. J Virol. 2007;81(4):202530. https://doi.org/10.1128/JVl.01718-06.

64. Tumpey TM, Szretter KJ, Van Hoeven N, Katz JM, Kochs G, Haller O, et al. The Mx1 gene protects mice against the pandemic 1918 and highly lethal human H5N1 influenza viruses. J Virol. 2007;81(19):10818-21. https://doi. org/10.1128/JVI.01116-07.

65. Seitz C, Frensing T, Hoper D, Kochs G, Reichl U. High yields of influenza A virus in Madin-Darby canine kidney cells are promoted by an insufficient interferon-induced antiviral state. J Gen Virol. 2010;91(Pt 7):1754-63. https:// doi.org/10.1099/vir.0.020370-0.

66. Seitz C, Isken B, Heynisch B, Rettkowski M, Frensing T, Reichl U. Trypsin promotes efficient influenza vaccine production in MDCK cells by interfering with the antiviral host response. Appl Microbiol Biotechnol. 2012; 93(2):601-11. https://doi.org/10.1007/s00253-011-3569-8.

67. Goto H, Kawaoka Y. A novel mechanism for the acquisition of virulence by a human influenza A virus. Proc Natl Acad Sci U S A. 1998;95(17):10224-8. https://doi.org/10.1073/pnas.95.17.10224.

68. Barnard DL. Animal models for the study of influenza pathogenesis and therapy. Antivir Res. 2009:82(2):A110-22. https://doi.org/10.1016/j.antiviral.2 008.12.014. 
69. Whitley RJ. Of ferrets and humans: influenza pathogenesis. J Infect Dis. 2010 201(7):976-7. https://doi.org/10.1086/651133.

70. Richard M, van den Brand JMA, Bestebroer TM, Lexmond P, de Meulder D, Fouchier RAM, et al. Influenza A viruses are transmitted via the air from the nasal respiratory epithelium of ferrets. Nat Commun. 2020;11(1):766. https:// doi.org/10.1038/s41467-020-14626-0.

71. Rimmelzwaan GF, Kuiken T, van Amerongen G, Bestebroer TM, Fouchier RA, Osterhaus AD. Pathogenesis of influenza A (H5N1) virus infection in a primate model. J Virol. 2001;75(14):6687-91. https://doi.org/10.1128/JVI.75.14. 6687-6691.2001.

72. Bissinger T, Fritsch J, Mihut A, Wu Y, Liu X, Genzel Y, et al. Semi-perfusion cultures of suspension MDCK cells enable high cell concentrations and efficient influenza A virus production. Vaccine. 2019;37(47):7003-10. https:// doi.org/10.1016/j.vaccine.2019.04.054.

73. Hoffmann E, Krauss S, Perez D, Webby R, Webster RG. Eight-plasmid system for rapid generation of influenza virus vaccines. Vaccine. 2002;20(25-26): 3165-70. https://doi.org/10.1016/S0264-410X(02)00268-2.

74. Genzel Y, Reichl U. Vaccine Production. In: Pörtner R, editor. Animal cell biotechnology: methods and protocols. Totowa, NJ: Humana Press; 2007. p. 457-73. https://doi.org/10.1007/978-1-59745-399-8_21.

75. Lambertz RLO, Pippel J, Gerhauser I, Kollmus H, Anhlan D, Hrincius ER, et al. Exchange of amino acids in the $\mathrm{H} 1$-haemagglutinin to $\mathrm{H} 3$ residues is required for efficient influenza A virus replication and pathology in Tmprss2 knock-out mice. J Gen Virol. 2018;99(9):1187-98. https://doi.org/10.1099/jgv. 0.001128 .

76. Kalbfuss B, Knochlein A, Krober T, Reichl U. Monitoring influenza virus content in vaccine production: precise assays for the quantitation of hemagglutination and neuraminidase activity. Biologicals. 2008;36(3):145-61. https://doi.org/10.1016/j.biologicals.2007.10.002.

77. Opitz L, Lehmann S, Reichl U, Wolff MW. Sulfated membrane adsorbers for economic pseudo-affinity capture of influenza virus particles. Biotechnol Bioeng. 2009;103(6):1144-54. https://doi.org/10.1002/bit.22345.

78. Frensing T, Heldt FS, Pflugmacher A, Behrendt I, Jordan I, Flockerzi D, et al. Continuous influenza virus production in cell culture shows a periodic accumulation of defective interfering particles. Plos One. 2013;8(9):e72288. https://doi.org/10.1371/journal.pone.0072288.

79. Hoffmann E, Stech J, Guan Y, Webster RG, Perez DR. Universal primer set for the full-length amplification of all influenza A viruses. Arch Virol. 2001; 146(12):2275-89. https://doi.org/10.1007/s007050170002.

80. Kawakami E, Watanabe T, Fujii K, Goto H, Watanabe S, Noda T, et al. Strandspecific real-time RT-PCR for distinguishing influenza VRNA, CRNA, and mRNA. J Virol Methods. 2011;173(1):1-6. https://doi.org/10.1016/j.jviromet.2 010.12.014.

81. Frensing T, Kupke SY, Bachmann M, Fritzsche S, Gallo-Ramirez LE, Reichl U. Influenza virus intracellular replication dynamics, release kinetics, and particle morphology during propagation in MDCK cells. Appl Microbiol Biotechnol. 2016;100(16):7181-92. https://doi.org/10.1007/s00253-0167542-4.

82. Pieler MM, Heyse A, Wolff MW, Reichl U. Specific ion effects on the particle size distributions of cell culture-derived influenza A virus particles within the Hofmeister series. Eng Life Sci. 2017;17(5):470-8. https://doi.org/10.1002/ elsc.201600153.

83. Hein M, Arora P, Marichal-Gallardo P, Winkler M, Genzel Y, Pöhlman S, et al. Purely clonal cell culture-derived defective interfering influenza virus particles: production, purification, and animal experiments. Mendeley Data. 2021. https://doi.org/10.17632/twpd8z76f7.1

\section{Publisher's Note}

Springer Nature remains neutral with regard to jurisdictional claims in published maps and institutional affiliations.

Ready to submit your research? Choose BMC and benefit from:

- fast, convenient online submission

- thorough peer review by experienced researchers in your field

- rapid publication on acceptance

- support for research data, including large and complex data types

- gold Open Access which fosters wider collaboration and increased citations

- maximum visibility for your research: over $100 \mathrm{M}$ website views per year

At BMC, research is always in progress.

Learn more biomedcentral.com/submissions 